\title{
Azacitidine combined with the selective FLT3 kinase inhibitor crenolanib disrupts stromal protection and inhibits expansion of residual leukemia-initiating cells in FLT3-ITD AML with concurrent epigenetic mutations
}

\author{
Anne-Kathrin Garz ${ }^{1,2}$, Saskia Wolf ${ }^{1}$, Sonja Grath ${ }^{3}$, Verena Gaidzik ${ }^{4}$, Stefan Habringer ${ }^{1,2}$, \\ Binje Vick ${ }^{2,5}$, Martina Rudelius ${ }^{6}$, Christoph Ziegenhain ${ }^{3}$, Sylvia Herold ${ }^{2,7}$, Marie- \\ Theresa Weickert ${ }^{1}$, Martha Smets ${ }^{3}$, Christian Peschel ${ }^{1,2}$, Robert A.J. Oostendorp ${ }^{1}$, \\ Sebastian Bultmann ${ }^{3}$, Irmela Jeremias ${ }^{2,5}$, Christian Thiede ${ }^{2,7}$, Konstanze Döhner ${ }^{4}$, \\ Ulrich Keller ${ }^{1,2}$ and Katharina S. Götze ${ }^{1,2}$ \\ ${ }^{1}$ Department of Medicine III, Klinikum rechts der Isar, Technische Universität München (TUM), Munich, Germany \\ ${ }^{2}$ German Cancer Consortium (DKTK) and German Cancer Research Center (DKFZ), Heidelberg, Germany \\ ${ }^{3}$ Department of Biology II, Ludwig-Maximilians-University (LMU), Munich, Germany \\ ${ }^{4}$ Department of Internal Medicine III, University of UIm, UIm, Germany \\ ${ }^{5}$ Helmholtz Zentrum München, German Research Center for Environmental Health, Munich, Germany \\ ${ }^{6}$ Department of Pathology, Heinrich-Heine University Düsseldorf, Düsseldorf, Germany \\ ${ }^{7}$ Department of Internal Medicine I, Gustav Carus University Dresden, Dresden, Germany \\ Correspondence to: Katharina S. Götze, email: katharina.goetze@tum.de \\ Keywords: FLT3-ITD, crenolanib, azacitidine, leukemia-initiating cell (LIC), TET2 \\ Received: May 18, 2017 Accepted: September 20, $2017 \quad$ Published: October 16, 2017 \\ Copyright: Garz et al. This is an open-access article distributed under the terms of the Creative Commons Attribution License 3.0 \\ (CC BY 3.0), which permits unrestricted use, distribution, and reproduction in any medium, provided the original author and source \\ are credited.
}

\section{ABSTRACT}

Effectively targeting leukemia-initiating cells (LIC) in FLT3-ITD-mutated acute myeloid leukemia (AML) is crucial for cure. Tyrosine kinase inhibitors (TKI) have limited impact as single agents, failing to eradicate LIC in the bone marrow. Using primary AML samples and a patient-derived xenograft model, we investigated whether combining the FLT3-selective TKI crenolanib with the hypomethylating agent azacitidine (AZA) eliminates FLT3-ITD LIC and whether efficacy of this combination depends on co-existing mutations. Using multiparameter flow cytometry, we show FLT3-ITD occurs within the most primitive Lin $/$ CD33(+)/CD45 dim/CD34+CD38- LIC compartment. Crenolanib alone could not target FLT3-ITD LIC in contact with niche cells while addition of AZA overcame stromal protection resulting in dramatically reduced clonogenic capacity of LIC in vitro and severely impaired engraftment in NSG mice. Strikingly, FLT3-mutated samples harboring TET2 mutations were completely resistant to crenolanib whereas neither NPM1 nor DNMT3A mutations influenced response. Conversely, primary AML LIC harboring either TET2, DNMT3A or NPM1 mutations did not show increased sensitivity to AZA.

In summary, resistance of FLT3-ITD LIC to TKI depends on co-existing epigenetic mutations. However, AZA + crenolanib effectively abrogates stromal protection and inhibits survival of FLT3-ITD LIC irrespective of mutations, providing evidence for this combination as a means to suppress residual LIC. 


\section{INTRODUCTION}

Acute myeloid leukemia (AML) with internal tandem duplications in the FLT3 tyrosine kinase (FLT3ITD) remains a disease with dismal prognosis. Despite intensive chemotherapy and allogeneic stem cell transplantation as post-remission therapy, relapses are frequent. First, second and third generation tyrosine kinase inhibitors (TKI) have been evaluated for FLT3-mutated AML with varying degrees of success and only transient responses as single agents [1-4].

Reasons for the limited success of TKI in FLT3mutated AML are diverse. Prolonged treatment with TKI leads to emergence of secondary kinase resistance mutations [5, 6]. Autocrine feedback loops in AML cells induce expression of FLT3 ligand (FL) [1]. Importantly, prevention of relapse requires complete eradication of the leukemic clone, including those rare leukemiainitiating cells (LIC) enriched in the $\mathrm{CD} 34^{+} \mathrm{CD} 38^{-}$bone marrow (BM) compartment and responsible for disease propagation $[7,8]$. LIC are protected from conventional chemotherapy by their BM microenvironment and we have previously shown that CD34+ ${ }^{+}$IC in FLT3-ITD AML persist and expand during treatment with first- and second generation TKI owing to their selective protection by stromal cells [9].

Developing more effective TKI and combining TKI with other novel agents such as epigenetic drugs are strategies currently being pursued in FLT3-ITD AML [10-12]. Several lines of evidence led us to hypothesize that combining a more selective FLT3 inhibitor with the hypomethylating agent azacitidine (AZA) may override the protective effect of the stromal microenvironment and thus more effectively eliminate LIC.

As a more potent FLT3 inhibitor, we chose crenolanib (creno), a promising new third-generation type I FLT3 inhibitor with high selectivity towards FLT3 [13, 14]. In contrast to type II TKI, it inhibits FLT3-ITD as well as TKD mutations by targeting both inactive and active conformational states and thus displays activity against kinase resistance mutations [13, 14]. In vitro studies have found creno to have superior cytotoxic effects compared to sorafenib (sora) or quizartinib and the compound is currently being evaluated in phase II trials in FLT3-ITD AML $[14,15]$. Azacitidine (AZA) has emerged as a promising drug for the treatment of elderly AML and is also being evaluated as an add-on to intensive induction chemotherapy $[16,17]$. Pre-emptive treatment with AZA can delay or prevent hematological relapses in AML with minimal residual disease, indicating it may have activity towards LIC [18]. In contrast to intensive chemotherapy, treatment with azacitidine does not appear to induce increased secretion of FL from the bone marrow $[10,19]$. Furthermore, resistance of FLT3-mutated LIC to TKI may be mediated by co-mutations, the most frequent being either NPM1 or epigenetic mutations (i.e. DNMT3A, TET2 and IDH1/2) [20, 21], which have have been postulated to show particular susceptibility to hypomethylating agents such as AZA [22-25]. Lastly, compensatory pathways upregulated in leukemia cells in response to TKI include survival pathways known to be mediated by stromal contact and which may be affected by AZA [26-29].

Here, using primary AML samples in vitro as well as in an in vivo xenograft model, we investigated whether creno in combination with AZA can eliminate LIC protected by stromal contact in FLT3-mutated AML and determined whether treatment response is dependent on co-existing genetic mutations in DNMT3A, NPM1 and TET2.

\section{RESULTS}

\section{FLT3-ITD is present within the $\mathrm{CD34}^{+} \mathrm{CD}^{-}$ LIC-enriched compartment concurrent with NPM1, DNMT3A and TET2 mutations}

The prerequisite for durable responses in AML therapy is the successful elimination of LIC in the BM. It is well established by next-generation sequencing (NGS) data that mutations in epigenetic regulators such as DNMT3A, TET2 and $I D H 1 / 2$ occur at a very early preleukemic stage within the primitive hematopoietic stem/ progenitor cell compartment. In contrast, FLT3-ITD is considered a late event in leukemogenesis, but may often be the crucial initiator for leukemic expansion [30]. Only limited data exist suggesting presence of FLT3-ITD in LIC and sophisticated sorting was not performed in these studies, nor were results correlated to epigenetic mutations (unknown at the time) [31,32]. Thus, to determine occurrence of FLT3-ITD in distinct phenotypically defined leukemic stem/progenitor subpopulations in relation to pre-leukemic and early leukemic hits, we analyzed ten FLT3-ITD AML samples (five CD34+ and five CD34, Table 1, patients \#1-10) by amplicon based sequencing of 54 genes related to myeloid neoplasms followed by flow cytometric sorting and targeted resequencing of identified alterations within leukemic stem/progenitor subpopulations (Figure 1A, Supplementary Figure 1A and Supplementary Table 1).

The mutational profile of our cohort was representative as it revealed a mean of 3.3 driver mutations per patient, concurrent with recent reports on the mutational landscape of AML [20,21]. NPM1 mutations were found in $7 / 10$ patients. In $7 / 10$ patients, epigenetic lesions in either TET2, IDH1, IDH2 or DNMT3A were found. $I D H 1 / 2$ mutations appeared exclusive, whereas two patients (\#4 and \#9) with DNMT3A mutations also carried a TET2 mutation. Only one patient (\#5) had FLT3-ITD as the sole mutation, but showed an aberrant $\mathrm{t}(6 ; 9)$ karyotype (Table 1, \#5; Supplementary Figure 1A).

Next, we separated blasts, committed progenitors and early stem cell compartments by multiparameter 
Table 1: AML patient sample characteristics

\begin{tabular}{|c|c|c|c|c|c|c|c|c|c|}
\hline ID & Age & Sex & Cytogenetics & $\begin{array}{c}F L T 3-\mathrm{ITD} / \mathrm{WT} \\
\text { ratio }\end{array}$ & NPM1 & DNMT3A & TET2 & Other & CD34 \\
\hline 1 & 58 & $\mathrm{~m}$ & 46, XY, del13(q) & 0.166 & wt & wt & wt & $\begin{array}{l}I D H 2, R U N X 1, \\
\text { SF3B1, STAG2 }\end{array}$ & Pos \\
\hline 2 & 81 & $\mathrm{~m}$ & $46, \mathrm{XY}$ & 0.713 & mut & wt & wt & neg & Pos \\
\hline 3 & 47 & $\mathrm{f}$ & $46, \mathrm{XX}$ & 0.62 & mut & wt & wt & $R A D 21$ & Pos \\
\hline 4 & 35 & $\mathrm{f}$ & $46, \mathrm{XX}$ & 0.848 & wt & mut & mut & $\begin{array}{l}\text { STAG2, GATA2, } \\
\quad(M L L-P T D)\end{array}$ & Pos \\
\hline 5 & 63 & $\mathrm{f}$ & $46, X X, t(6 ; 9)$ & 0.23 & wt & wt & wt & neg & Pos \\
\hline 6 & 68 & $\mathrm{~m}$ & $46, \mathrm{XY}$ & 0.18 & mut & wt & mut & neg & Neg \\
\hline 7 & 31 & $\mathrm{f}$ & $46, \mathrm{XX}$ & 0.63 & mut & wt & $\mathrm{wt}$ & $C E B P A, I D H 1$ & Neg \\
\hline 8 & 69 & $\mathrm{~m}$ & $49, \mathrm{XY},+\mathrm{Y},+21,+22$ & 0.302 & mut & wt & $\mathrm{wt}$ & IDH1 & Neg \\
\hline 9 & 63 & $\mathrm{f}$ & $46, \mathrm{XX}$ & 0.559 & mut & mut & mut & $W T 1$ & Neg \\
\hline 10 & 74 & $\mathrm{f}$ & $46, \mathrm{XX}$ & 0.98 & mut & wt & mut & NPM1, TET2 & Neg \\
\hline 11 & 36 & $\mathrm{~m}$ & $46, \mathrm{XY}$ & 5.141 & mut & mut & wt & n.a. & Pos \\
\hline 12 & 59 & $\mathrm{~m}$ & $46, X Y, i(14)(q 10)$ & 1.707 & wt & wt & $\mathrm{wt}$ & n.a. & Pos \\
\hline 13 & 43 & $\mathrm{f}$ & $46, X X, \operatorname{add}(19)(13.1)$ & 0.582 & wt & wt & wt & n.a. & Pos \\
\hline 14 & 41 & $\mathrm{f}$ & $\begin{array}{c}\text { 46, XX, t }(9 ; 11) \\
(\mathrm{p} 22 ; \mathrm{q} 23)\end{array}$ & 0.789 & wt & wt & wt & n.a. & Pos \\
\hline 15 & 59 & $\mathrm{f}$ & $46, \mathrm{XX}$ & 0.799 & mut & wt & mut & n.a. & Neg \\
\hline 16 & 66 & $\mathrm{~m}$ & $46, \mathrm{XY}$ & 8.911 & mut & mut & wt & n.a. & n.a. \\
\hline 17 & 64 & $\mathrm{~m}$ & n.a. & 0.625 & mut & mut & $\mathrm{wt}$ & n.a. & n.a. \\
\hline 18 & 70 & $\mathrm{~m}$ & n.a. & 0.095 & wt & wt & mut & n.a. & n.a. \\
\hline 19 & 51 & $\mathrm{~m}$ & n.a. & 0.861 & wt & wt & $\mathrm{wt}$ & n.a. & n.a. \\
\hline 20 & 46 & $\mathrm{f}$ & $46, \mathrm{XX}$ & 1.687 & mut & mut & $\mathrm{wt}$ & n.a. & Neg \\
\hline 21 & 63 & $\mathrm{f}$ & $\begin{array}{c}46, \mathrm{XX}, \\
\mathrm{i}(14)(\mathrm{q} 10) 46, \text { idem, } \\
\mathrm{t}(\mathrm{X} ; 3)(\mathrm{p} 11 ; \mathrm{p} 13)\end{array}$ & 0.854 & wt & mut & wt & n.a. & Neg \\
\hline 22 & 78 & $\mathrm{f}$ & $46, \mathrm{XX}$ & 0.552 & mut & wt & mut & n.a. & Neg \\
\hline 23 & 72 & $\mathrm{f}$ & $46, \mathrm{XX}$ & 0.4 & mut & n.a. & n.a. & n.a. & Pos \\
\hline 24 & 75 & $\mathrm{f}$ & $46, \mathrm{XX}$ & 0.8 & wt & mut & wt & $J A K 2$ & Pos \\
\hline 25 & 59 & $\mathrm{f}$ & $46, X X$ & 0.513 & mut & mut & wt & n.a. & Neg \\
\hline 26 & 35 & $\mathrm{~m}$ & $46, \mathrm{XY}$ & 0.836 & mut & wt & wt & n.a. & Neg \\
\hline 27 & 61 & $\mathrm{f}$ & $46, \mathrm{XX}$ & 0.649 & wt & wt & wt & RUNX1, NRAS & Pos \\
\hline 28 & 66 & $\mathrm{~m}$ & $46, X Y$ & 0.151 & mut & mut & wt & n.a. & Neg \\
\hline 29 & 77 & $\mathrm{f}$ & $46, X X$ & 0.237 & mut & wt & mut & n.a. & Neg \\
\hline 30 & 83 & $\mathrm{f}$ & $47, X X,+4$ & 0.937 & mut & mut & mut & n.a. & Pos \\
\hline 31 & 84 & $\mathrm{~m}$ & $46, X Y$ & 0.885 & mut & wt & mut & n.a. & Neg \\
\hline 32 & 76 & $\mathrm{~m}$ & $\begin{array}{l}\text { 46, XY, } \\
\text { complex }\end{array}$ & 1.294 & $\mathrm{wt}$ & mut & mut & n.a. & Pos \\
\hline
\end{tabular}

M, male; f, female; mut, mutated; wt, wild-type; n.a., not available. 

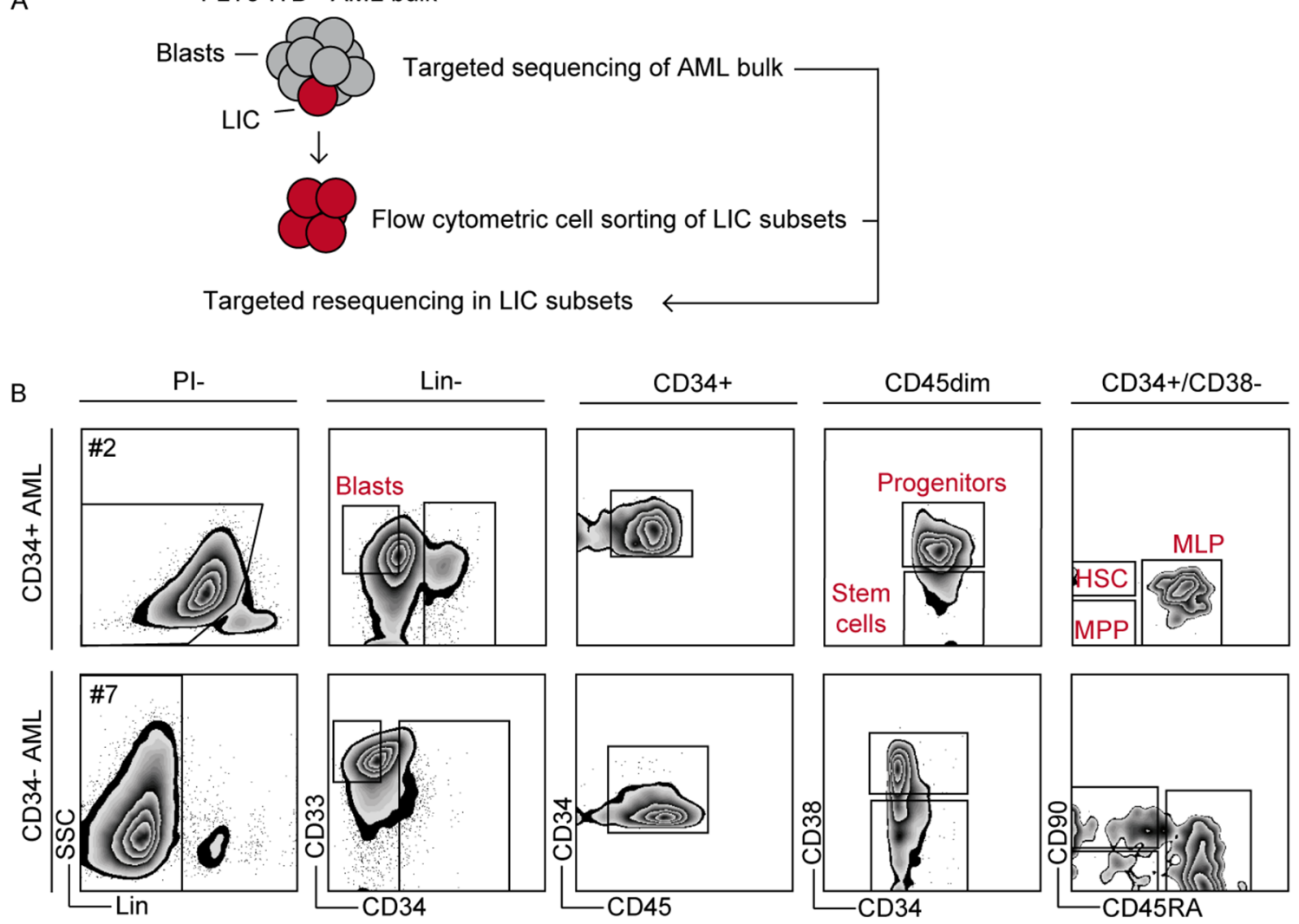

C

\begin{tabular}{|l|c|c|c|c|c|}
\cline { 2 - 6 } \multicolumn{1}{c|}{} & \multicolumn{3}{c|}{ CD34+ AML } & \multicolumn{2}{c|}{ CD34- AML } \\
\cline { 2 - 6 } \multicolumn{1}{c|}{} & $\# 2$ & $\# 3$ & $\# 4$ & $\# 7$ & \#9 \\
\hline Blasts & & & & & \\
\hline Progenitors & & & & & failed \\
\hline Stem cells & & & & & \\
\hline MLP & & & & & \\
\hline MPP & & & & & n.a. \\
\hline HSC & & & n.a. & n.a. & n.a. \\
\hline & 0 & \multicolumn{3}{l}{} \\
\cline { 2 - 6 } & 100 FLT3-ITD VAF [\%]
\end{tabular}

\begin{tabular}{|c|c|c|c|c|c|}
\hline \multirow{3}{*}{ Gene mutation } & \multirow{2}{*}{\multicolumn{2}{|c|}{$\frac{\text { CD34+ AML }}{\# 4}$}} & \multicolumn{3}{|c|}{ CD34- AML } \\
\hline & & & \multirow{2}{*}{$\begin{array}{c}\# 7 \\
\mathrm{IDH} 1 \\
\end{array}$} & \multicolumn{2}{|c|}{$\# 9$} \\
\hline & TET2 & DNMT3A & & TET2 & DNMT3A \\
\hline \multicolumn{6}{|l|}{ Blasts } \\
\hline \multicolumn{6}{|l|}{ Progenitors } \\
\hline \multicolumn{6}{|l|}{ Stem cells } \\
\hline \multicolumn{6}{|l|}{ MLP } \\
\hline MPP & & failed & & n.a. & n.a. \\
\hline $\mathrm{HSC}$ & n.a. & n.a. & n.a. & n.a. & n.a. \\
\hline c & 0 & 100 VAF & & & \\
\hline
\end{tabular}

Figure 1: Detection of FLT3-ITD and concurrent gene mutations in leukemic stem/progenitor compartments. Experimental design (A). Gating strategy for multiparameter flow cytometric sorting of CD34+ and CD34- AML BM samples. Blasts (Lin $/$

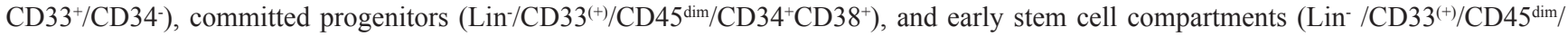
$\left.\mathrm{CD}^{+} 4^{+} \mathrm{CD} 38\right)$ ) i.e. MLP $\left(\mathrm{CD}^{2} 5 \mathrm{RA}^{+}\right)$, MPP $\left(\mathrm{CD} 45 \mathrm{RA}^{-} \mathrm{CD} 90^{-}\right)$and $\mathrm{HSC}\left(\mathrm{CD} 45 \mathrm{RA}^{-} \mathrm{CD} 90^{+}\right)$. Representative plots for a $\mathrm{CD} 34^{+} \mathrm{AML}$ (upper panel, Table 1 patient " 2 ) and CD34- AML sample (lower panel, Table 1 patient ${ }^{\#} 7$ ) are shown (B). gDNA was isolated from sorted compartments and mutations in FLT3, NPM1, DNMT3A, TET2 and IDH1/2 genes were detected by targeted resequencing. Variant allele frequencies (VAF, \%) of FLT3-ITD (C, upper panel) and epigenetic mutations (C, lower panel) in sorted populations are shown. n.a., not available (e.g. population not found). 
flow cytometry based on the expression of CD33 as a known marker aberrantly expressed on LIC [33]. We found that the early leukemic stem cell compartment

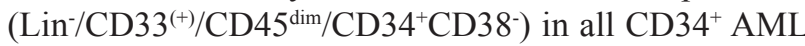
samples (\# 2, 3, 4, 5) was dominated by multilymphoid progenitors (MLP, CD45RA ${ }^{+}$), whereas in CD34- AML, we also found multipotent progenitors (MPP, CD45RA $\mathrm{CD}^{-}$) and hematopoietic stem cells (HSC, CD45RA $\mathrm{CD}^{+}, \mathrm{A7}$ ), consistent with published reports (Figure 1B and Supplementary Figure 1B) [34]. In all 5/10 AML samples where we were able to detect and sort leukemic HSC and MPP populations, FLT3-ITD was present in these fractions and variant allele frequencies (VAF) hierarchically increased from there (Figure 1C upper panel and Supplementary Table 1), indicating dominant clonal hematopoiesis. NPM1 mutations were present in all analyzed compartments (Supplementary Table 1). DNMT3A, TET2, IDH1/2 mutations were present in early and late leukemic stem/progenitor compartments with equally high VAF (Figure 1C lower panel and Supplementary Table 1), concurrent with the concept that these are founder mutations $[35,36]$.

In summary, we demonstrate that FLT3-ITD, NPM1, DNMT3A and TET2 mutations frequently co-occur within the most primitive phenotypically definable Lin $/$

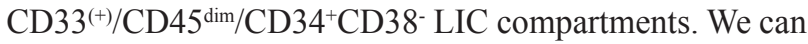
therefore ascertain that FLT3-ITD is indeed an appropriate TKI target for LIC elimination in AML. However, cooccurrence of NPM1, TET2 and DNMT3A mutations in this same compartment may influence response of FLT3mutated LIC to TKI.

\section{FLT3-ITD cells are protected against crenolanib by stromal niche cells despite effective inhibition of FLT3-ITD signaling}

Before evaluating the efficacy of creno to target FLT3-ITD LIC, we confirmed the FLT3-ITD-selective effects of creno in leukemia cell lines. Creno was cytotoxic to murine $\mathrm{Ba} / \mathrm{F} 3$ cells transduced with human FLT3-ITD (Ba/F3_FLT3-ITD) as well as FLT3-ITD human leukemia cell lines MV4-11 and MOLM-13 in a dose-dependent manner whereas no effect was observed on $\mathrm{Ba} / \mathrm{F} 3$ cells transduced with FLT3 wild-type receptor (Ba/F3_FLT3$\mathrm{WT}$ ) or the leukemia cell line RS4;11 (Figure 2A, upper panel). Creno-induced cell death was maximal at a concentration of $100 \mathrm{nM}$ at 96 hours in FLT3-ITD cells (Figure 2A, lower panel) and FLT3 phosphorylation was effectively inhibited at $50 \mathrm{nM}$, as was phosphorylation of downstream targets STAT5, AKT and ERK (Figure 2B). Thus, we used a creno concentration of $100 \mathrm{nM}$ for further experiments [14].

To test whether creno as single agent can induce cell death in FLT3-ITD driven Ba/F3 cells protected by stromal cells, we made use of an established in vitro coculture system with the osteoblast-like murine embryonic cell line EL08-1D2 mimicking the BM niche and shown to effectively protect FLT3-ITD leukemia cells [9]. As previously observed by us and others, leukemia cells showed increased viability when cultured on stromal cells, highlighting their dependency on the BM microenvironment for survival $[9,37,38]$. Ba/F3 FLT3ITD cells were sensitive to creno only when cultured in suspension, but almost completely protected from cytotoxic effects by culture on EL08-1D2 cells (Figure $2 \mathrm{C}$ ), indicating that like first and second generation TKI, creno alone cannot effectively target FLT3-ITD cells in their niche. Linear regression analyses of this data showed a statistically significant interaction between stroma and creno, underscoring the conclusion that stroma confers resistance to creno in FLT3-mutated leukemia cells (complete statistical analyses in Supplementary data). Efficacy of creno to inhibit FLT3-ITD was not perturbed by stromal contact, as shown by persistent inhibition of pFLT3 and downstream targets pSTAT5, pAKT and pERK in the presence of stroma (Figure 2D and Supplementary Figure 2).

\section{Stromal resistance of $F L T 3-I T D$ AML cells to creno is overcome by addition of AZA}

We then asked whether stromal resistance of FLT3-ITD cells to creno can be modulated by AZA. Azacitidine was added in vitro as a single dose on day 1 of the cell culture. Previously published analyses have shown that at $37^{\circ} \mathrm{C}$ azacitidine is stable in solution and induces distinct epigenetic changes in cells cultured for at least 72 hours after addition of the drug [39, 40]. Dose titration revealed that MV4-11 and MOLM-13 were only marginally sensitive to AZA up to $10 \mu \mathrm{M}$ (Figure 3A), the dose corresponding to the maximum plasma concentration achieved in patients receiving AZA treatment [39, 41, 42]. Using this dose for further experiments, we assessed induction of apoptosis in FLT3ITD homozygous MV4-11 cells cultured in suspension and on EL08-1D2 stromal layers in the presence of creno, AZA and the combination thereof (Figure 3B). Simultaneous combination of TKI and AZA induced most pronounced apoptosis of FLT3-ITD AML cells although stromal resistance was not overcome within 4 days of treatment (Supplementary Figure 3). As AZA incorporates into DNA as well as RNA, its anti-neoplastic effects are cell-cycle dependent and independent, respectively. Within four days, MV4-11 cells divide twice. Therefore, we asked whether combination therapy with AZA and TKI could be improved by prolonged drug exposure over 8 days (Figure 3B). The dependence of AML cells on stromal contact for survival was even more pronounced under prolonged culture conditions, as evidenced by reduced viability of untreated cells in suspension. Pro-longed Co-culture on stroma significantly increased viability of AML cells. AZA as a single agent did still not induce cell 

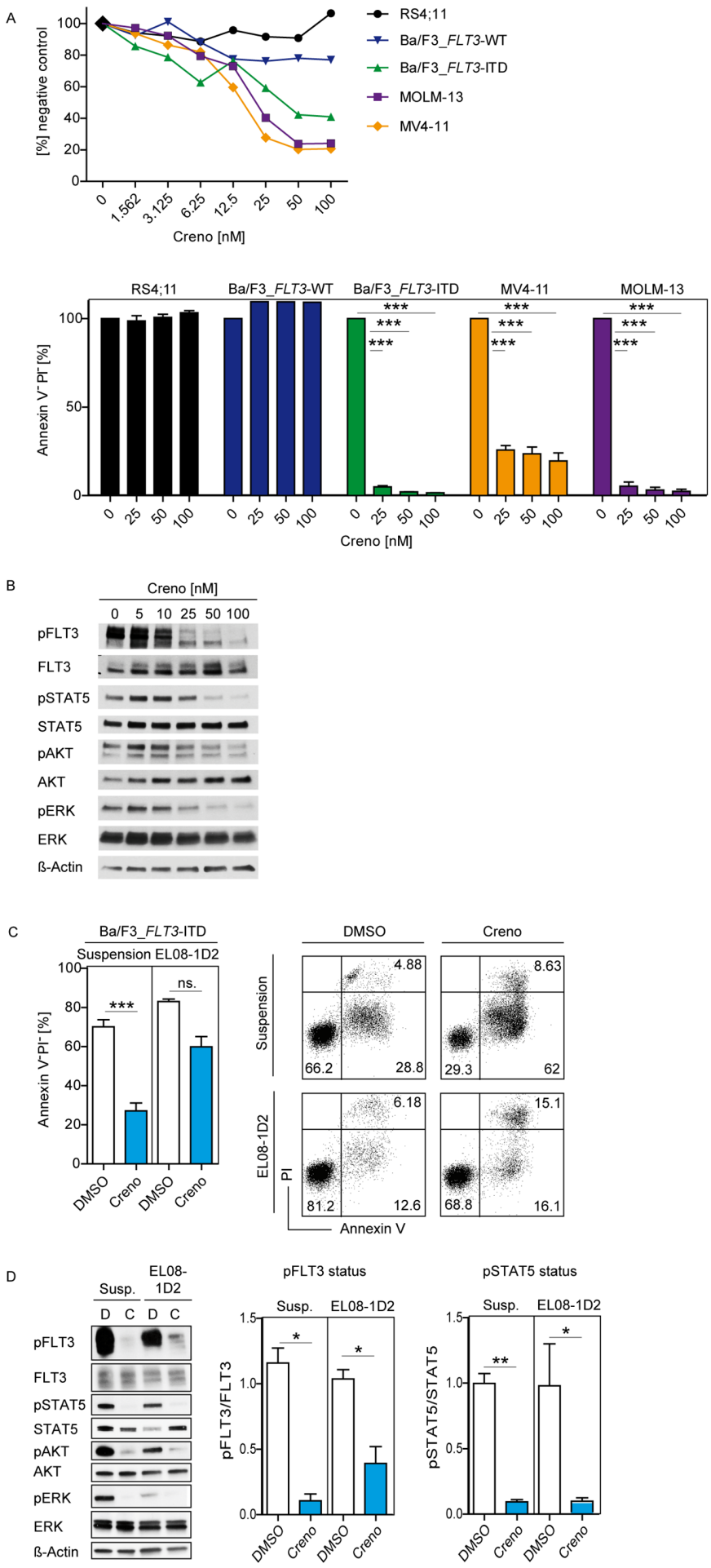

Figure 2: Efficacy of creno against FLT3-ITD leukemia cells is counteracted by stromal contact. Dose response for leukemia cells treated with creno for 96 hours. Cell viability was determined by MTT assay. Results shown are mean \pm SEM of triplicates (A, upper panel). Induction of cell death was measured by Annexin/PI staining of leukemia cells after treatment with creno (100 nM) for 96 hours. Percentage of live cells (defined as Annexin $\mathrm{V}^{-} / \mathrm{PI}^{-}$) was determined by flow cytometry. Results shown are mean $\pm \mathrm{SEM}$ of triplicates (A, lower panel). Inhibition of FLT3-ITD signaling pathways assessed in Ba/F3_FLT3-ITD cells by immunoblotting after treatment with indicated creno concentrations for 1 hour. A representative blot is shown (B). Ba/F3_FLT3-ITD cells were treated with DMSO or $100 \mathrm{nM}$ creno in suspension or co-culture with EL08-1D2 for 24 hours. Results are shown as mean \pm SEM of 3 independent experiments $(\mathbf{C}$, left panel), and representative FACS plots (C, right panel). Representative immunoblot of FLT3-ITD signaling in Ba/F3 FLT3-ITD cells after treatment in mono- or co-culture (D, left panel). Intensity of FLT3- and STAT5-phosphorylation is shown as mean \pm SEM of 3 independent experiments (D, right panel). 


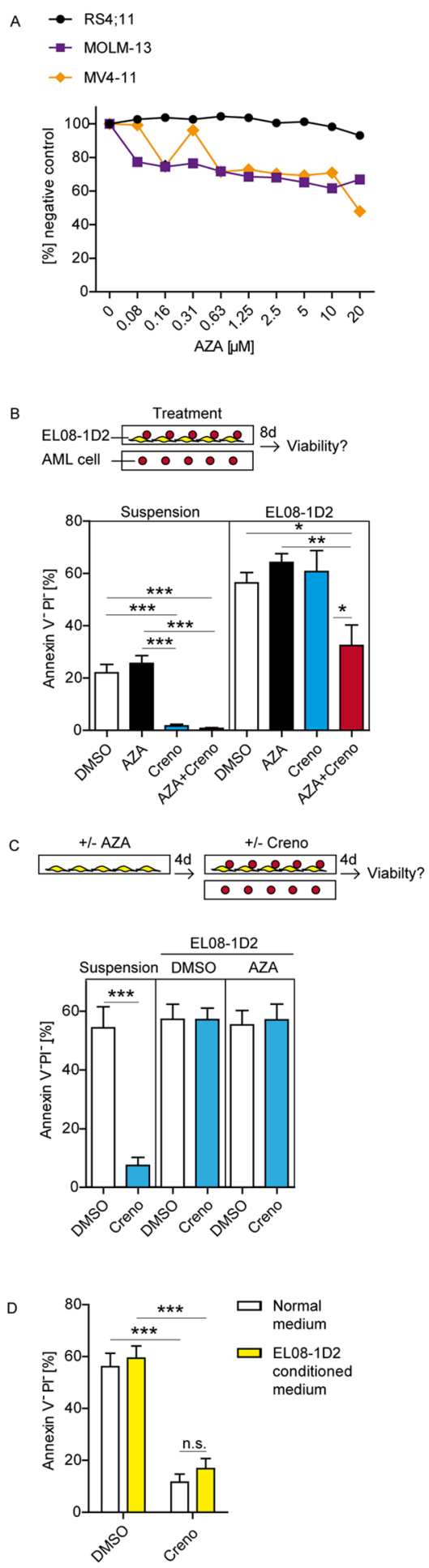

Figure 3: The addition of AZA to creno can overcome stromal resistance of $F$ LT3-ITD leukemia cells. Dose response for FLT3-ITD leukemia cells treated with AZA was determined by MTT after 96 hours. Results are shown as mean \pm SEM of triplicates (A). MV4-11 cells were cultured in suspension or on stromal EL08-1D2 layers. Cultures were treated on day 1 with either DMSO, $10 \mu \mathrm{M}$ AZA, $100 \mathrm{nM}$ creno or in combination. Induction of cell death was measured by Annexin V/PI staining after 8 days. Results are shown as mean \pm SEM of three independent experiments (B). EL08-1D2 cells were cultured in the presence or absence of $10 \mu \mathrm{M}$ AZA for 4 days. The stromal cell layer was washed twice with PBS, MV4-11 cells were added and co-cultures were treated with DMSO or $100 \mathrm{nM}$ creno for 4 days. AML cells were harvested and cell death was measured by Annexin V/PI staining, Results are shown as mean \pm SEM of three independent experiments (C). MV4-11 cells were cultured in standard medium or medium preconditioned by EL08-1D2 cells for 4 days. Cells were treated with $100 \mathrm{nM}$ creno for 4 days and induction of cell death was measured as described above, Results are shown as mean \pm SEM of three independent experiments (D). 
death. However, combined treatment with creno and AZA effectively reduced stromal resistance of FLT3-ITD AML cells indicated by significant induction of cell death in the presence of stroma (Figure $3 \mathrm{~B}$ ) and positive interaction testing by linear regression analyses (complete statistical analyses in Supplementary data). Nearly identical results were obtained with FLT3-ITD heterozygous MOLM13 cells as well as using sora in combination with AZA (Supplementary Figures 3 and 4). Pre-treatment of EL081D2 cells with AZA did not sensitize MV4-11 cells to creno (Figure 3C) and stroma-derived soluble factors could not protect MV4-11 cells from creno (Figure 3D), implying that AZA perturbs stromal protection by effect on the direct interaction between FLT3-ITD cells and their niche.

\section{TKI response of FLT3-ITD LIC is dependent on concurrent genetic mutations}

To translate our findings back to the situation in the patient, we then assayed LIC-enriched $\mathrm{CD} 34^{+}$cells from primary FLT3-ITD AML in our established in vitro BM model. A 4-day co-culture period was chosen for the primary samples as we have previously shown that $\mathrm{CD} 34^{+}$ AML stem/progenitor cells divide at least once during this time period without losing expression of CD34 and prolonged in vitro culture of primary AML cells may lead to drug-independent loss of viability [9].

In vitro treatment with creno, AZA or the combination was followed by colony forming cell assays (CFC) to determine short- as well as long-term proliferative potential characteristic of LIC (Figure 4A). We then correlated results with the presence of $D N M T 3 A$, NPM1 and TET2 mutations (Table 1). These are among the most common co-occurring mutations with FLT3-ITD and of particular interest in regard to epigenetic agents such as AZA $[20,25,43]$.

In comparison to DMSO, AZA as a single agent reduced short-term and long-term colony growth of LIC by $49 \%$ and $37 \%$, respectively (Figure $4 \mathrm{~A}$ ). As expected from our cell line data, creno alone did not prevent expansion of committed leukemic progenitors with shortterm (CFU) or LIC with long-term proliferative potential (LTC) on stroma. Strikingly, the combination of AZA and creno eliminated $89 \%$ of short-term and $64 \%$ of long-term LIC despite stromal contact (Figure 4A). Of note, stromal protection of FLT3-ITD LIC towards inhibition by creno was not due to reactive FL secretion. Levels of stromaderived FL were below detection threshold by ELISA regardless of treatment condition (data not shown) while levels of LIC-derived FL were unchanged (Supplementary Figure 5).

Contrary to expectation, response to AZA as a single agent was not influenced by presence of DNMT3A, NPM1 or TET2 mutations as determined by short-term and longterm proliferative potential (Figure 4B). Most strikingly,
TET2 mutations conferred resistance to creno alone, and FLT3-ITD/TET2mut cells expanded significantly during creno treatment, as evidenced by increased CFC numbers compared to DMSO in FLT3-ITD/TET2-mutated samples (Figure 4C). In contrast, neither DNMT3A nor NPM1 mutations had an influence on response to creno (Figure 4C).

Higher FLT3-ITD/WT ratios have been demonstrated to increase sensitivity towards TKI with published ratios ranging from 0.5-0.78 [44, 45]. Accordingly, in FLT3-ITD AML without TET2 mutations only long-term LIC with a FLT3-ITD/WT ratio $>0.78$ were effectively targeted by creno while leukemic progenitors with a ratio $<0.78$ were not sensitive (Figure 5).

Importantly, the combination of AZA and creno effectively targeted FLT3-ITD LIC regardless of FLT3ITD/WT ratios or concurrent mutations.

\section{AZA + creno inhibits engraftment capacity of FLT3-ITD LIC}

To recapitulate our in vitro results with primary AML samples, we made use of a patient-derived xenograft (PDX) AML mouse model. PDX models faithfully mimic patient characteristics and thus are a powerful tool to define drug efficacy and resistance in leukemia [46, 47]. Primary FLT3-ITD AML samples were serially transplanted into NSG mice with reliable and reproducible engraftment for several passages, proving presence of LIC. Targeted resequencing of $\mathrm{PDX}$ cells demonstrated that driver mutations present in the founding clone of the original AML were preserved during passaging [46]. We tested the in vivo engraftment capacity of two separate FLT3-ITDmutated PDX samples (Table 2) after in vitro treatment for 4 days with DMSO, creno, AZA or the combination of both (Figure 6A). Of note, our experimental read-out focused on the engraftment behavior of residual nicheprotected LIC after drug treatment, which models the patient's situation at post-remission. It is technically nearly impossible to model post-remission treatment with presence of dormant LIC in vivo (at least we are not aware of any such-like AML mouse model).

$\begin{array}{cr}\text { In the first PDX } & \text { cohort (FLT3- } \\ \text { ITD/NPMImut/DNMT3Amut), engraftment was }\end{array}$ monitored by serial PB sampling. At 7 weeks posttransplant, PDX cells ( $\mathrm{mCD} 45 / \mathrm{hCD}^{\circ} / \mathrm{hCD}^{+} 3^{+}$) were detected in $\mathrm{PB}$ of all mice in the DMSO cohort (mean $5.28 \%$; range $3.33-7.14 \%$ ), at which point all mice were sacrificed. PDX cells in PB were also detected in the AZA (mean 2.87\%; range 1.16-5.74\%), creno (mean 2,22\%; range $0.85-4.41 \%$ ) and AZA + creno (mean $1.29 \%$; range $0.97-1.81 \%$ ) groups. Strikingly, PDX infiltration of BM as assessed by FACS and IHC was significantly reduced in mice transplanted with AZA + creno-treated FLT3-ITD cells compared to DMSO control or AZA alone (Figure $6 \mathrm{~B}$ and $6 \mathrm{C})$. 


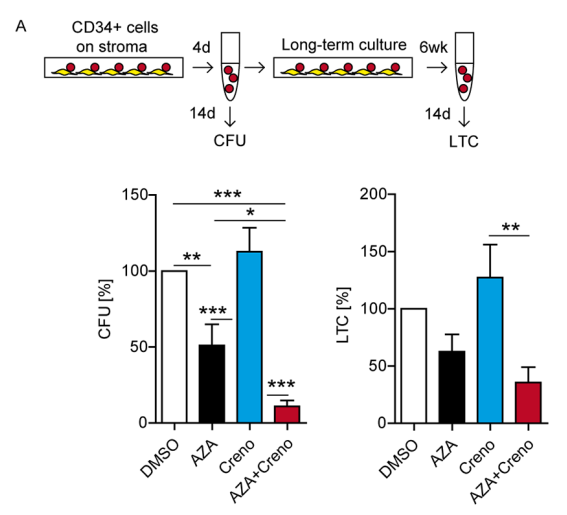

B
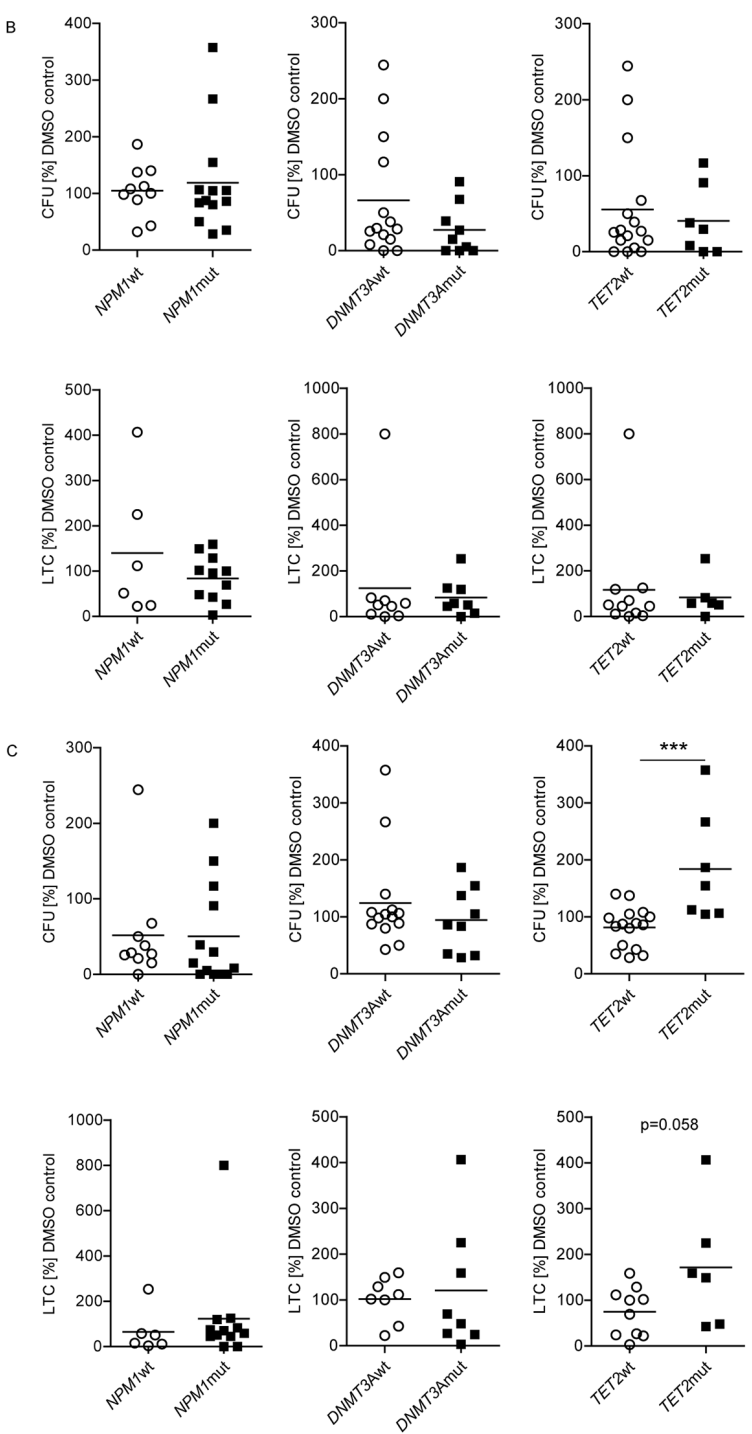

Figure 4: Sensitivity of primary FLT3-ITD LIC to crenolanib is dependent on concurrent epigenetic gene mutations. Experimental design: enriched CD34 $4^{+} F L T 3-$ ITD BM cells were cultured on EL08-1D2 stroma and treated on day 1 with DMSO, $10 \mu \mathrm{M}$ AZA, $100 \mathrm{nM}$ creno or the combination thereof. Cells were harvested after 4 days. Progenitor activity was assessed by short-term colonyforming unit assay (CFU) in methylcellulose. Long-term LIC capacity (long-term culture-derived colony-forming cells, LTC) was assessed after 6 weeks on irradiated (30 Gy) EL08-1D2 cells followed by plating in methylcellulose. Colonies were scored after 14 days using standard criteria. Results are shown as mean CFU $(n=23 \pm$ SEM) and LTC frequencies $(n=17 \pm$ SEM) in relation to DMSO controls (A). Response to AZA alone regarding co-mutations in NPM1 (CFU n = 23; LTC $\mathrm{n}=18$ ), DNMT3A (CFU $\mathrm{n}=23$; LTC $\mathrm{n}=17$ ), TET2 (CFU $\mathrm{n}$ $=23$, upper panels; $\mathrm{LTC} \mathrm{n}=17$, lower panels) (B). Response to creno alone regarding co-mutations in NPM1 (CFU $\mathrm{n}=23$; $\mathrm{LTC} \mathrm{n}=18)$, DNMT3A (CFU n $=23 ;$ LTC n $=16)$, TET2 $($ CFU $\mathrm{n}=23 ;$ LTC n $=16)($ C $)$. 
Table 2: PDX sample characteristics [46]

\begin{tabular}{|c|c|c|c|c|c|c|c|c|}
\hline \multirow[b]{2}{*}{ ID } & \multirow[b]{2}{*}{ Age } & \multirow[b]{2}{*}{ Sex } & \multirow[b]{2}{*}{ Disease stage } & \multirow[b]{2}{*}{ Cytogenetics } & \multicolumn{4}{|c|}{ VAF of driver mutation in PDX (patient) } \\
\hline & & & & & $\begin{array}{c}F L T 3-I T D / W T \\
\text { ratio }\end{array}$ & NPM1 & DNMT3A & $T E T 2$ \\
\hline AML361 & 40 & $\mathrm{~F}$ & Initial & Normal & 0.31 & 0.48 & 0.47 & wt \\
\hline AML602 & 40 & $\mathrm{~F}$ & Relapse & $\begin{array}{l}\text { Aberrant } \\
\text { complex }\end{array}$ & 0.39 & 0.39 & wt & 0.39 \\
\hline
\end{tabular}

In the second PDX cohort (FLT3ITD/NPM1mut/TET2mut) stable expression of luciferase enabled monitoring of engraftment by luciferin-induced bioluminescence. BLI signals were first detected in the BM of extremities and sternum 4 weeks posttransplantation. Notably, during the first 35 days, leukemic expansion of FLT3-ITD/NPM1mut/TET2mut cells was significantly accelerated in the creno treatment group compared to DMSO controls (Figure 7A). After 8 weeks, leukemia was spread over the whole body in $5 / 5$ mice in the DMSO group, in 3/5 mice in the AZA group and in $4 / 5$ mice in the creno group, at which point all the mice were sacrificed. In the AZA + creno group, only one mouse was highly infiltrated and no BLI signal was detectable in 2/5 mice until the end of BLI measurement (Figure 7B, Supplementary Figure 6). We verified BLI findings by FACS analysis and IHC. Corresponding to our CFC data (Figure 4C), BM infiltration by FLT3ITD/NPM1mut/TET2mut PDX cells was increased in the creno cohort compared to DMSO control, while it was decreased in the AZA group and further significantly reduced in the AZA + creno cohort (Figure 7B and
7C), in which normal BM architecture was preserved as assessed by IHC (Figure 7B). Thus, our PDX data confirm that TET2 mutations confer resistance and growth advantage in response to crenolanib as a single agent.

Thus, as proven by impaired engraftment of two different FLT3-ITD mutated PDX samples in NSG mice, the combination of AZA and creno abrogates stromal protection and effectively diminishes residual LIC in FLT3-ITD AML irrespective of cooperating genetic mutations. Of note, the two PDX samples differed in their cytogenetics, with the TET2-mutated sample showing a complex aberrant karyotype while the DNMT3A-mutated sample exhibited a normal karyotype (Table 2). To our knowledge, there is no data indicating an influence of aberrant karyotypes on the efficacy of TKI in FLT3-ITD AML. However, most studies on FLT3-TKI have been performed in normal karyotype AML which is by far the most common cytogenetic subgroup [48]. Thus, we cannot completely exclude that the different cytogenetics may have an influence on our results, although this seems unlikely.

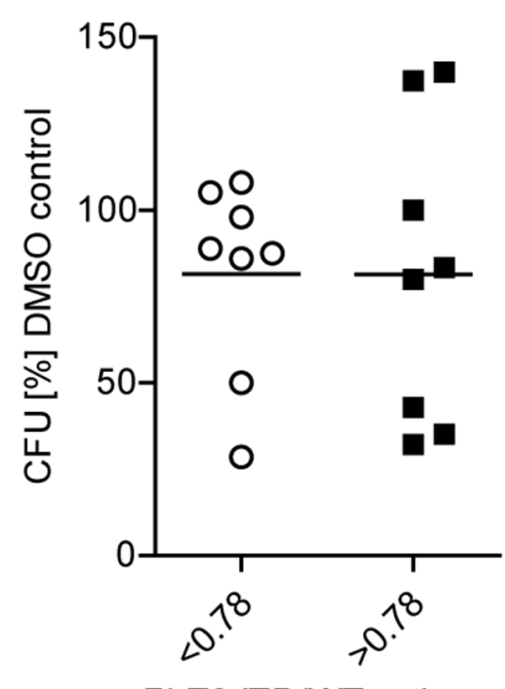

FLT3-ITD/WT ratio

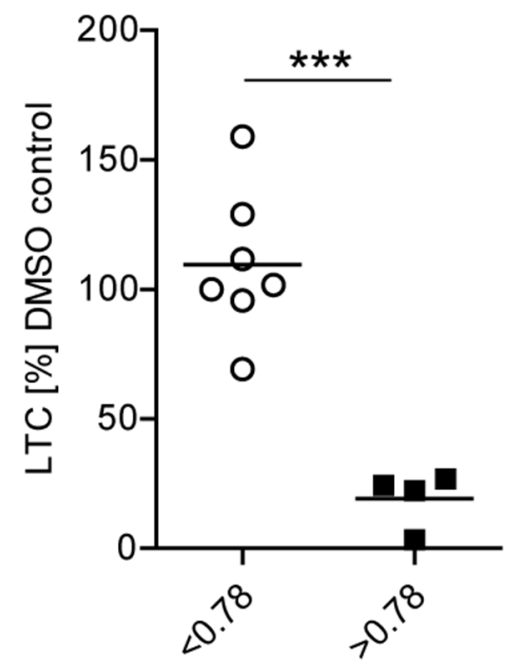

FLT3-ITD/WT ratio

Figure 5: Sensitivity of primary FLT3-ITD LIC to creno is dependent on FLT3-ITD/WT ratio in the absence of TET2 mutations. Analysis of CFU $(\mathrm{n}=16)$ and LTC $(\mathrm{n}=11)$ capacity of FLT3-ITD/TET2wt samples in relation to FLT3-ITD/WT ratios after 4-day treatment with creno in the in vitro BM model. 
A

AML BM Serial transplantation

sample Ex vivo treatment

B
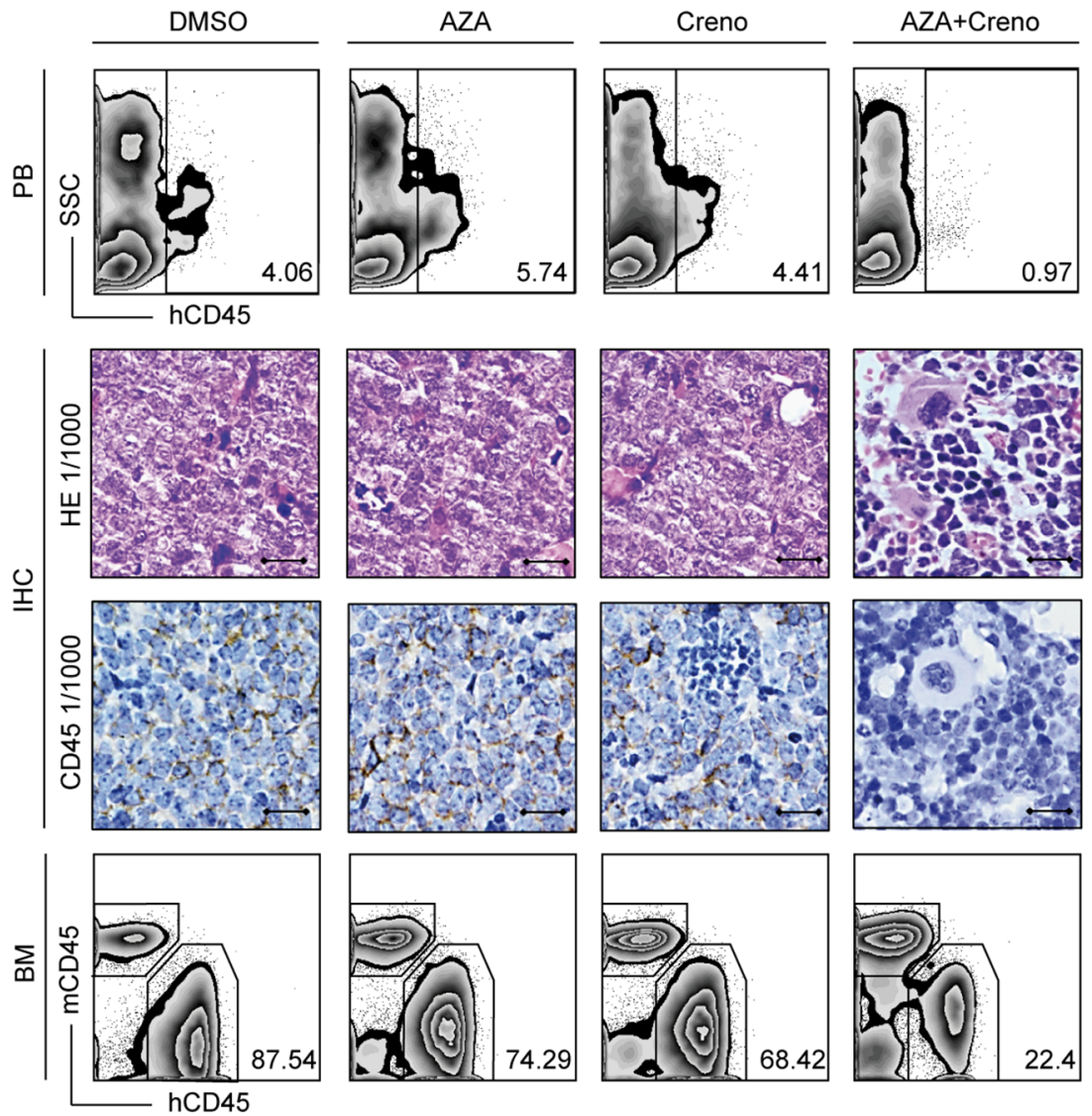

C
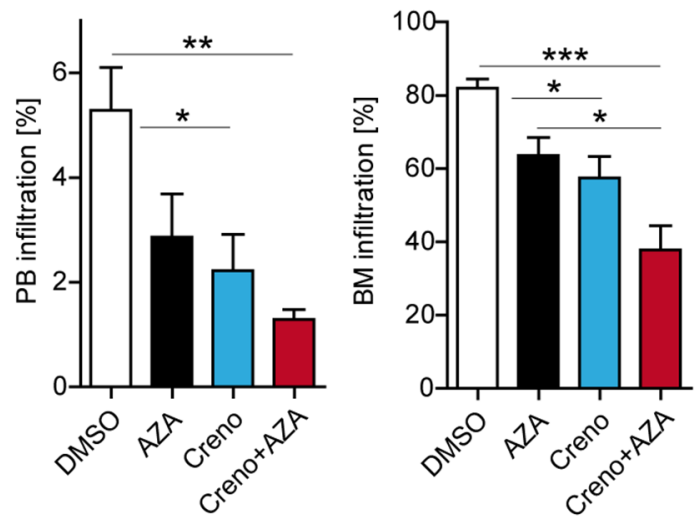

Figure 6: AZA + creno impairs engraftment capacity of FLT3-ITD LIC in a PDX mouse model. Experimental design: PDX cells (AML sample "361) were cultured in vitro on EL08-1D2 stroma and treated on day 1 with DMSO, $10 \mu \mathrm{M}$ AZA, $100 \mathrm{nM}$ creno or the combination thereof. PDX cells were harvested after 4 days and $2 \times 10^{5}$ viable cells were injected IV into NSG mice ( $\mathrm{n}=20$ per experiment) (A). Representative images of FLT3-ITD/NPMImut/DNMT3Amut PDX infiltration was analyzed by flow cytometry of PB (top) and BM (bottom) as well as immunohistochemistry (IHC) (middle; Scale bar, $10 \mu \mathrm{m}$ ) of femurs visualized by hematoxylin-eosin (H\&E) staining or expression of human CD45 (hCD45) (B). Statistical summary of PB and BM infiltration in NSG mice, mean of $\mathrm{n}=5$ per condition \pm $\operatorname{SEM}(\mathbf{C})$. 


\section{AZA modulates gene expression pattern of engaged LIC and niche cells}

To delineate in how far stromal protection of FLT3-ITD LIC is modulated by treatment, we evaluated the individual gene expression pattern by RNAseq of co-cultured FLT3-ITD/NPM1mut/DNMT3Amut PDX cells (AML sample \#361, Table 2) with EL08-1D2 cells after in vitro treatment with DMSO, AZA, creno or the combination (Figure 8A).

Strikingly, interaction of PDX cells with EL08-1D2 cells in co-culture altered the gene expression pattern of both cell types compared to monoculture control cells (Figure 8B, up- and downregulated genes in the DMSO lane), illustrating active engagement. Pathway analyses and functional GO annotation of the top 100 differentially expressed genes between DMSO-control and treatments revealed on the PDX side enrichment of genes in extracellular-matrix-receptor interaction (Figure 8C, Table 3, Supplementary data). On the EL08-1D2 side, analysis highlighted genes involved in signaling pathways shown to promote a leukemic microenvironment, e.g. NF-kappB, HIF-1 and TNF signaling (Table 4, Supplementary data). Of note, this gene expression pattern was partially reversed through treatment with AZA alone and in combination with crenolanib while crenolanib alone induced a less visible, slightly different pattern (Figure 8B). The emerging differences in gene expression pattern provide further evidence that AZA effectively impairs LIC-niche interaction and thus overcomes stromal resistance against crenolanib treatment.

\section{DISCUSSION}

In order to cure AML, any effective therapy must eliminate the chemo-resistant, quiescent and self-renewing LIC enriched within the $\mathrm{CD} 34^{+} \mathrm{CD} 38^{-}$population of the BM. Eradication of LIC in FLT3-ITD AML by FLT3TKI has thus far remained an elusive goal. Here, using multiparameter flow cytometry in combination with targeted sequencing, we detected FLT3-ITD within the

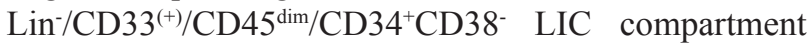
beginning at the level of HSC or MPP, i.e. in the same early compartment as mutations in NPM1, DNMT3A or TET2 inferred by NGS data. This is in line with recent data demonstrating that either DNMT3A or TET2 mutations together with FLT3-ITD alone are sufficient to transform murine HSC and induce AML in mouse models $[49,50]$. Thus, although FLT3-ITD may be subclonal in some leukemias and is sometimes lost at relapse, our data ascertain the validity of FLT3-ITD as a TKI target to eliminate LIC.

Nevertheless, the highly FLT3-selective TKI crenolanib alone could not effectively target stromaprotected FLT3-ITD LIC in our in vitro BM model. Although LIC with higher FLT3-ITD/WT ratios were more sensitive to creno, this only held true for samples without TET2 mutations. FLT3-ITD/TET2mut LIC were completely resistant to creno as a single agent in the presence of stroma and expanded upon TKI treatment with CFC results corroborated by our PDX transplant data. In support of our primary human data, TKI insensitivity has been observed in FLT3-ITD/TET2 $2^{-/}$murine progenitors as well [49]. This observation warrants confirmation in a larger clinical cohort as it may have important implications for tailoring of TKI therapy in FLT3-ITD AML.

Since $I D H$ mutations inhibit TET2 function and induce a similar leukemic signature as TET2 mutations [51], it is tempting to speculate that $I D H$ mutations may also confer resistance to TKI in FLT3-ITD AML. Unfortunately, we were unable to investigate this due to the limited number of $I D H$-mutated AML samples in this study.

Strikingly, addition of AZA to creno effectively overcame niche protection of FLT3-ITD LIC in vitro, resulting in significantly reduced expansion in CFC assays despite concurrent NPM1, DNMT3A or TET2 mutations. In addition, engraftment ability of in vitro-treated FLT3ITD PDX cells was severely impaired, providing further evidence we are targeting FLT3-ITD LIC with long-term proliferative potential. Translated to the clinical setting, this would suggest that the combination of AZA + creno could be employed as maintenance therapy to suppress residual LIC.

Conflicting data has been reported on the correlation between clinical response to AZA and the presence of $D N M T 3 A$ or TET2 mutations in retrospective analyses, but data from prospective trials have not been reported thus far $[16,17,23,24,52,53]$. In our cohort directly testing AZA on primary FLT3-ITD LIC, the presence of NPM1, DNMT3A or TET2 mutations did not confer a better response to AZA alone, arguing against a direct link between AZA efficacy and epigenetic mutations. Furthermore, despite many efforts, a clear correlation between DNA demethylation and response to AZA has not been able to be demonstrated. The fact that AZA is incorporated to a large part into RNA (up to $90 \%$ ) and only to a smaller percentage into DNA [25, 54], suggests that the observed effect of AZA on stromal resistance of FLT3-ITD LIC may also be mediated via the RNA level and not only by DNA demethylation.

Indeed, our RNA-seq data suggest that several pathways involved in the complex interaction between LIC and their niche were actively disrupted by AZA that warrant further investigation. Crosstalk between LIC and the niche is not dependent on one single mechanism but is a dynamic process mediated by diverse mechanisms including cellular and soluble mediators. Surely, we were not able to depict the entire complexity of stromal TKI resistance of LIC in our in vitro co-culture assays. However, at least in our experimental setup, TKI resistance was not mediated by reactive FL secretion as has been 
A

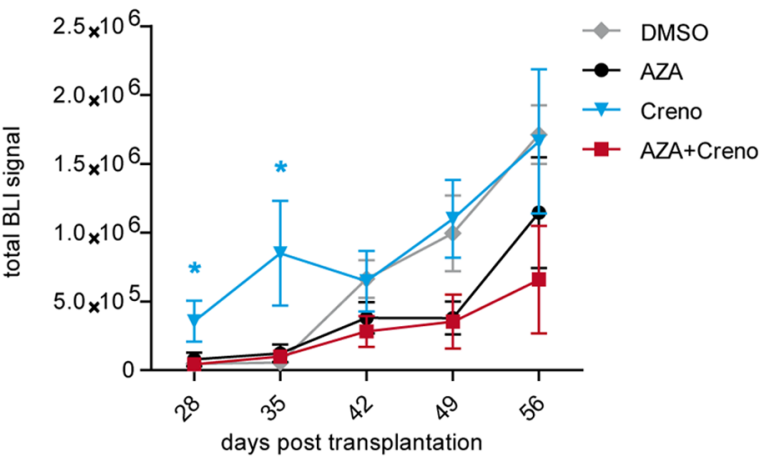

B
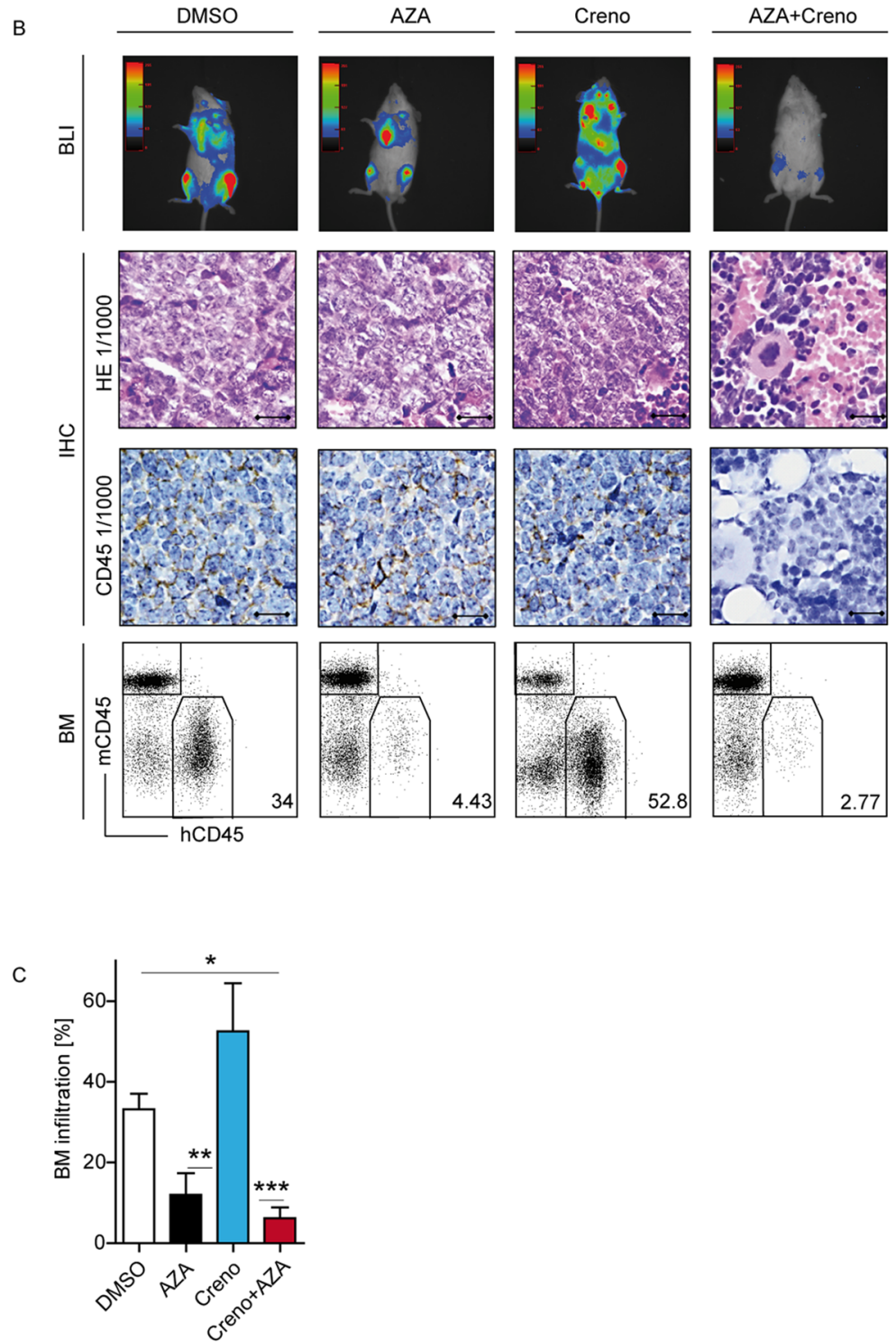

Figure 7: In vivo expansion of residual FLT3-ITD/NPM1mut/TET2mut PDX cells is enhanced after crenolanib monotherapy. PDX cells (AML sample ${ }^{\# 602)}$ were cultured in vitro on EL08-1D2 stroma and treated with DMSO, $10 \mu M$ AZA, 100 $\mathrm{nM}$ creno or the combination thereof added on day 1. PDX cells were harvested on day 4 and $2 \times 10^{5}$ viable cells were injected IV into NSG mice ( $\mathrm{n}=20$ per experiment). AML infiltration in NSG mice was monitored by noninvasive BLI in vivo imaging. Time course of bioluminescence signals in NSG cohorts, mean of $n=5$ per condition \pm SEM (A). Representative BLI one day before sacrifice are shown $(\mathbf{B}$, top). IHC of femurs (B, middle) visualized by H\&E staining and expression of hCD45. Scale bar, $10 \mu \mathrm{m}$. FACS plots of BM (B, bottom). Statistical summary of BM infiltration in PDX transplanted NSG mice (mean of $n=5$ per condition \pm SEM) (C). 
described previously [19] or niche-derived soluble factors, but was dependent on direct association between LIC and niche cells. To analyze and validate each of these pathways was beyond the scope of this project but will be performed in future work. In itself, the diversity of RNA and DNA-dependent pathways by which AZA may exert its anti-leukemic activity argues that the multimodality of mechanisms is key to effectively overcoming stromal resistance so as to enable creno to specifically target FLT3-ITD LIC in their niche. It therefore seems unlikely that targeting a singular pathway involved in stromal protection may recapitulate this effect.

To our knowledge, this is the first work studying the effect of TKI and AZA on different mutational genotypes in primary human FLT3-ITD AML. We demonstrate that efficacy of TKI therapy in FLT3-mutated AML is highly dependent on the mutational landscape within each leukemia and provide a valuable framework for designing rational combination therapy in FLT3-ITD AML. The recently reported encouraging results of the RATIFY trial

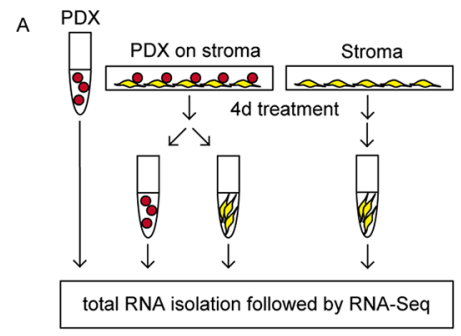

B
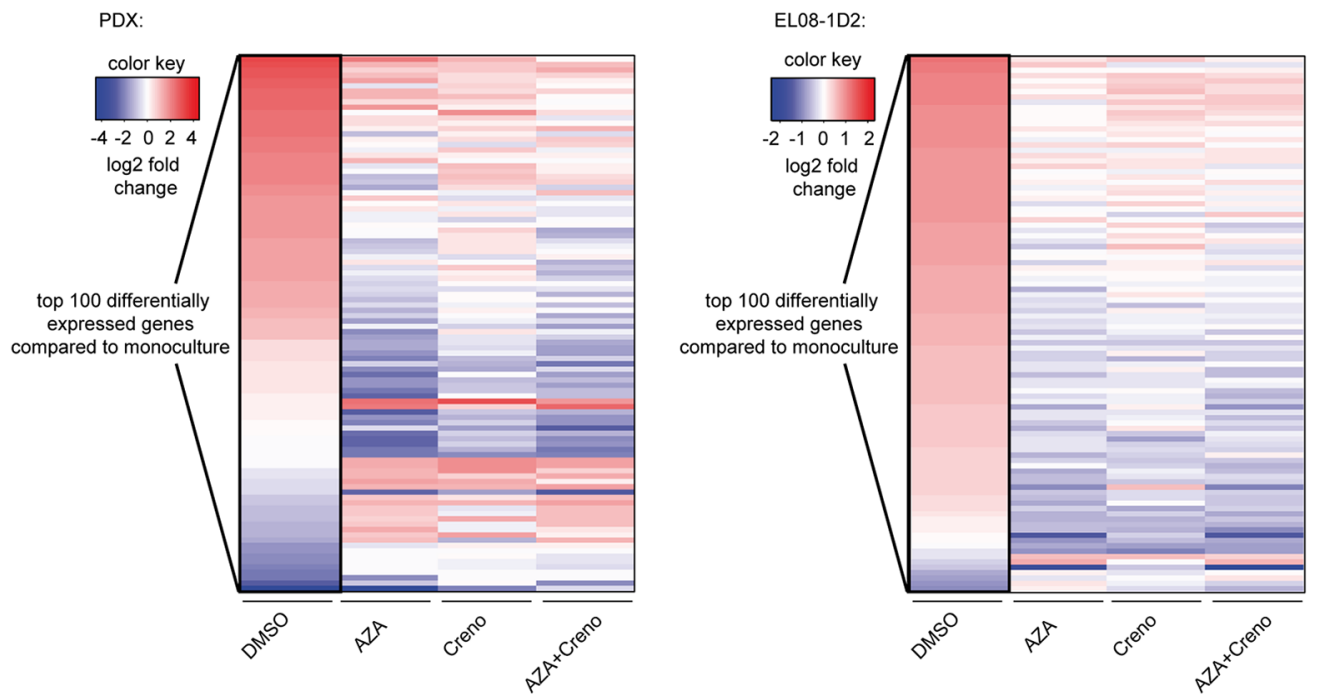

C

Biological process
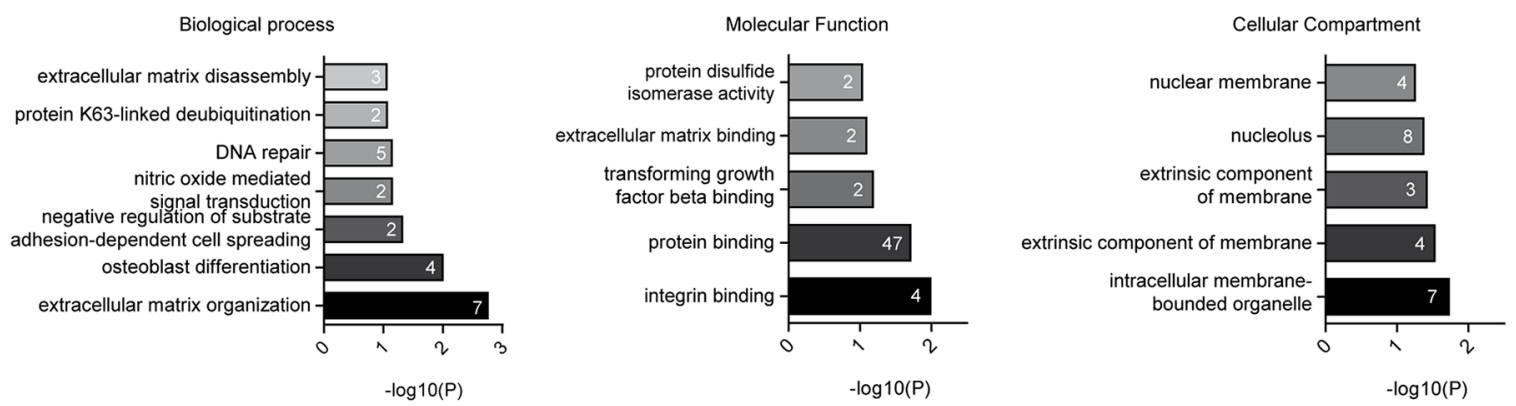

Figure 8: RNA sequencing analyses of FLT3-ITD PDX cells and EL08-1D2 stromal cells reveal changes after treatment in co-culture. Experimental design: Total RNA was isolated from PDX and EL08-1D2 cells, either in monoculture (untreated) or cocultured and treated on day 1 with DMSO, $10 \mu \mathrm{M}$ AZA, $100 \mathrm{nM}$ creno or the combination and cultured for 4 days in vitro. Four replicates were processed and analyzed for each condition (A). First, we estimated the differential gene expression (log 2 fold change, standard DESeq2 analysis) between stroma and LIC alone versus co-cultured cells. Then, log2 fold changes for the 100 most differentially expressed genes were ranked in ascending order, to visualize how treatment with AZA, creno or AZA + creno affected interaction of LIC and stroma in comparison to DMSO controls. Red and blue colors display up- and downregulation (log 2-fold change) of the 100 most differentially expressed genes in comparison to monoculture controls (B). GO annotation for PDX genes. The number of significantly $(\mathrm{p}<0.05)$ enriched genes per GO category are indicated (C). 
Table 3: Pathway analysis in PDX cells

KEGG Pathways

Significantly enriched genes

hsa04512:ECM-receptor interaction

CD36, COL5A2, SPP1

Table 4: Pathway analysis in niche cells

\begin{tabular}{lc}
\hline KEGG Pathways & Significantly enriched genes \\
\hline mmu04620:Toll-like receptor signaling pathway & Tab2, Chuk, Cxcl10, Lbp \\
mmu04064:NF-kappa B signaling pathway & Tab2, Chuk, Lbp \\
mmu04066:HIF-1 signaling pathway & Serpine1, Egln1, Vegfa \\
mmu04668:TNF signaling pathway & Tab2, Chuk, Cycl10, Lbp \\
mmu05200:Pathways in cancer & Arhgef12, Chuk, Rock1, Egln1, Vegfa \\
mmu04270:Vascular smooth muscle contraction & Arhgef12, Npr2, Rock1 \\
\hline
\end{tabular}

show that combining the unselective TKI midostaurin with intensive chemotherapy results in a survival benefit for FLT3-ITD AML patients, but it is uncertain how much of this effect is due to inhibition of FLT3 as opposed to off-target effects of midostaurin [55]. Our data suggest that testing patients with FLT3-ITD AML for TET2 mutations should be considered before initiation of more selective FLT3-TKI therapy and that the combination of AZA + TKI could be employed as a means to suppress residual LIC.

\section{MATERIALS AND METHODS}

\section{Cell lines and reagents}

MV4-11, MOLM-13 and RS4;11 cell lines were obtained from and propagated as suggested by the German Collection of Microorganisms and Cell Cultures (DMSZ), were authenticated by DMSZ by DNA typing and PCR analysis as well as cytogenetic testing, and passaged for $<6$ months after receipt. EL08-1D2 stromal cells were used up to passage 12 and cultured as described [9]. Ba/ F3 FLT3-WT and Ba/F3 FLT3-ITD cells were generated as described previously [56]. All cytokines were purchased from R\&D Systems. Creno (Selleckchem, Munich, Germany) and AZA (Celgene Corp, Munich, Germany) were freshly prepared directly before use following the manufacturers' instructions.

\section{Bone marrow samples}

BM samples were obtained from newly diagnosed AML patients recruited to the German AMLSG trials or from the Munich Leukemia Laboratory (MLL). Written informed consent in accordance with the Declaration of Helsinki was obtained from all patients according to protocols approved by the Ethics Committee of the TUM. Samples were screened for presence of FLT3ITD, DNMT3A, NPM1, TET2 and IDH1/2 mutations as described [48]. Mononuclear cells (MNC) were isolated from BM using Bicoll separating solution and stored in liquid nitrogen until use. Patient sample characteristics are summarized in Table 1.

\section{Flow cytometric sorting (FACS) of leukemic blast, progenitor and stem cell compartments}

MNC from FLT3-ITD AML BM samples were stained for lineage markers using biotinylated antibodies: CD4 (RPA-T4; Biolegend), CD8a (RPA-T8; Biolegend), CD19 (HIB19; Biolegend), CD41 (MEM-06; Sigma), CD235alpha (HIR2; eBioscience), CD56 (B159; BD Pharmingen). Cells were then stained with the following fluorochrome-conjugated antibodies: CD34-FITC (581; BD Pharmingen), CD90-PE (5e10; BD Pharmingen), CD33-PC5.5 (D3HL60, Beckmann Coulter), CD45RAAPC Cy7 (H1100; BD Pharmingen), Streptavidin-eFluor 450 (eBioscience), CD38-APC (HB7; BD Pharmingen), CD45-APC-Cy7 (2D1; BD Pharmingen). PI was added as live/dead marker. Cell sorting was performed on a FACS Aria II (Becton Dickinson, Heidelberg, Germany). Sorting purity of $>98 \%$ was routinely obtained.

\section{gDNA Isolation of FACS-sorted stem cell compartments}

gDNA was isolated from sorted AML subpopulations using the ZR Viral DNA Kit ${ }^{\mathrm{TM}}$ (Zymo 
Research, Freiburg, Germany) for $<2 \times 10^{5}$ cells and the QIAamp DNA Micro Kit (Qiagen, Hilden, Germany) for $>2 \times 10^{5}$ cells according to the manufacturers' instructions.

\section{Targeted sequencing of AML bulk and sorted subpopulations}

Molecular alterations in the gDNA from AML bulk samples (AML samples \#1-10) were evaluated by targeted sequencing using the TruSight Myeloid assay (Illumina, Chesterford, UK) which covers the following 54 genes or gene hotspots related to myeloid neoplasms: $B C O R$, BCORL1, CDKN2A, CEBPA, CUX1, DNMT3A, ETV6, EZH2, IKZF1, KDM6A, PHF6, RAD21, RUNX1, STAG2 and ZRSR2 and oncogenic hotspots of ABL1, ASXL1, ATRX, $B R A F, C A L R, C B L, C B L B, C B L C, C D K N 2 A, C S F 3 R$, FBXW7, FLT3, GATA1, GATA2, GNAS, HRAS, IDH1, IDH2, JAK2, JAK3, KIT, KRAS, MLL, MPL, MYD88, NOTCH1, NPM1, NRAS, PDGFRA, PTEN, PTPN11, SETBP1, SF3B1, SMC1A, SMC3, SRSF2, TET2, TP53, $U 2 A F 1$ and $W T 1$. For preparation of target enrichment libraries, $50 \mathrm{ng}$ of genomic DNA were used and prepared as recommended in the manufacturers' protocol (TruSight Myeloid Sequencing Panel Reference Guide 15054779 v02, Illumina). Samples were paired-end sequenced (2x225 bp) on a MiSeq sequencer using MiSeq Reagent Kits V3 (Illumina). Sequence data alignment of demultiplexed FastQ files, variant calling and filtering was done using the Sequence Pilot software package (JSI medical systems GmbH, Germany) with default settings and a 5\% variant allele frequency (VAF) mutation calling cut-off. Detection of large insertions and deletions was performed using PINDEL algorithm following BWA-MEM mapping with default settings $[57,58]$. Human genome build HG19 was used as reference genome for mapping algorithms.

Analysis in gDNA extracted from sorted AML subpopulations (AML samples \#2-4, 6-7, 9) was done using targeted resequencing based on individual amplicons generated specifically for the affected regions. Deep sequencing was performed on MiSeq (Illumina) or IonTorrent PGM (Thermo Fisher Scientific, Darmstadt, Germany) platforms with a minimum coverage of 10,000 reads.

\section{Cell viability assays}

Dose-dependent cytotoxicity was determined by colorimetric quantification of dimethyl-thiazole diphenyl tetrazolium bromide (MTT; Promega) according to the manufacturer's instructions. To determine cell death, cells were washed and stained in Annexin/PI buffer containing $1 \mathrm{M}$ Hepes, $2.5 \mathrm{M} \mathrm{NaCl}, 1.62 \mathrm{mM} \mathrm{CaCl}$, and APCAnnexin V (BD Biosciences) and PI was added. Flow cytometric analyses were performed on a CyAn ADP Lx P8 (Beckman Coulter). Data were processed with FlowJo software (TreeStar Inc, Ashland, Oregon, USA).

\section{Western blot analysis}

SDS-PAGE and immunoblotting were performed as previously described [9]. Cells were collected and washed in ice-cold PBS containing $1 \mathrm{mM} \mathrm{Na} 2 \mathrm{VO} 4$ and shock frozen in liquid nitrogen. Cell pellets were thawed on ice and incubated in lysis buffer. After 15 minutes, lysates were sonicated. Cell debris was removed by centrifugation at full speed for 15 minutes at $4^{\circ} \mathrm{C}$ in a microcentrifuge. Supernatants were collected and the protein concentration was estimated using the DC Protein Assay Kit II following the manufacturers' instructions. Protein absorption was measured at $750 \mathrm{~nm}$ using the ELx800 Universal Microplate reader and the Microplate Manager 5.2. software. $30 \mu \mathrm{g}$ protein were taken up in loading dye, boiled at $95^{\circ} \mathrm{C}$ for 10 minutes and separated in 4-15\% Mini Protean TGX stain free gels by SDS-PAGE in 1X Running Buffer in an electrophoresis chamber. The gel was blotted onto PVDF membranes in transfer buffer in a wet-transfer device. After blocking in 5\% BSA or milk in TBS-T, membranes were incubated overnight at $4{ }^{\circ} \mathrm{C}$ with the following primary antibodies: FLT3/FLK2 (1:1000), pFLT3 (Tyr591) (1:1000), ERK1 (1:1000), pERK (1:1000), Stat5 (1:1000), pStat5(Tyr 694) (1:1000), AKT (1:1000), pAKT (Ser473) (1:1000), or $\beta$-actin (1:2000). After washing with TBS-T, anti-rabbit or anti-mouse IgG ECL HRP-linked secondary antibodies were added for 20 minutes at RT. Membranes were washed with TBS and visualized on Kodak films using the enhanced chemiluminescence (ECL)-method (SuperSignal West). Signal intensity was analyzed using the ImageJ software. Antibodies were stripped off the membranes using Amido Black Stain solution.

\section{Culture of primary AML cells}

MNC from FLT3-ITD BM samples were enriched for $\mathrm{CD}_{3} 4^{+}$cells by magnetic bead separation (Miltenyi Biotech Bergisch Gladbach, Germany). CD $34^{+}$cells were cultured on EL08-1D2 in serum-free medium (SFM) with 5 growth factors (5 GF): kit ligand (KL), Flt3-ligand (FL), thrombopoietin (TPO), interleukin-6 (IL-6) and interleukin-3 (IL-3) as described [9]. Cells were treated with creno $(100 \mathrm{nM})$, DMSO or AZA (10 uM) on day 1 of the culture as indicated. After 4 days, $\mathrm{CD} 34^{+}$cells were harvested and assayed for short-term colony-forming units (CFU) and long-term culture-derived colony-forming cells (LTC) as described [9].

\section{PDX xenograft mouse model}

Animal studies were performed in agreement with the Guide for Care and Use of Laboratory Animals published by the US National Institutes of Health (NIH Publication No. 85-23, revised 1996), in compliance with German law on the protection of animals, and with approval of the responsible regional authorities. NOD. $\mathrm{C}_{\mathrm{g}}-P_{r k d c^{\text {scid }}} \mathrm{IL} 2 \mathrm{rg}^{\text {tml } l w_{j} /} / \mathrm{Sz}$ mice (NSG; The Jackson 
Laboratory, Bar Harbour, ME) were maintained at the animal facility of the TUM.

FLT3-ITD AML patient derived xenograft (PDX) cells and transgenic PDX cells which express firefly luciferase were generated by serial passaging in NSG mice as described [46]. PDX cells were cultured on EL08-1D2 cells and treated with DMSO, AZA, creno or both for 4 days in vitro. Cells were harvested and viable cells were enumerated by trypan blue exclusion. A total of $2 \times 10^{5}$ viable cells (per mouse) in $200 \mu \mathrm{lBS}$ were injected into the tail vein of non-irradiated 6 to 16 -week-old NSG mice. To monitor engraftment, peripheral blood (PB) samples were collected every other week beginning week 6 after PDX injection from the facial vein of NSG mice and analyzed by flow cytometry.

Transgenic PDX engraftment in NSG mice was repetitively monitored by bioluminescence in vivo imaging (BLI). Mice were narcotized and injected with D-luciferin (BIOMOL, Germany) intraperitoneally to activate recombinant luciferase. Images were taken using a charge-coupled device camera, equipped with an image intensifier for 10-120 seconds, bin size 2, gain 900 (OrcaII ER, Hamamatsu, Japan) as previously described [59]. The SimplePCI software (Hamamatsu) was used to display and quantify BLI signals.

Mice were sacrificed when PB sampling or BLI indicated systemic AML in the DMSO-treated mice. PDX cells were re-isolated from PB, femurs, tibiae and spines. After erythrocyte lysis, cells were stained with the following antibodies for flow cytometry: hCD45 APC-Cy7 (BD Pharmingen, 2D1), hCD34-FITC (BD Pharmingen, 581), hCD33-PC5.5 (Beckmann Coulter, D3HL60.251), mCD45-APC (eBioscience, 30-F11), Cell Trace Violet (Life Technologies). Flow cytometric analyses were performed on a CyAn ADP Lx P8 (Beckman Coulter, Krefeld, Germany). Data were processed with FlowJo software (TreeStar, Inc).

\section{Immunhistochemistry}

Tissue sections were deparaffinized. Antigen retrieval was carried out by pressure cooking in citrate buffer ( $\mathrm{pH} \mathrm{6)}$ for 7 minutes. Anti-human CD45 was detected after 1-hour incubation at room temperature by the Mouse on Mouse kit (Abcam) according to the manufacturer's protocol. Slides were evaluated using an Olympus BX53 microscope (x100 objective, Olympus, Germany) and images taken with an Olympus DP26 camera (Olympus).

\section{RNA sequencing}

Total RNA was isolated from murine EL08-1D2 and human PDX cells using RNeasy Mini Kit (Qiagen). RNA sequencing (RNA-seq) library preparation and data processing was performed according to the Unique
Molecular Identifiers (UMI) sequencing protocol, a modified bulk single-cell RNA barcoding and sequencing (SCRB)-seq protocol [60].

Briefly, cDNA libraries were prepared from $5 \mathrm{ng}$ RNA per sample. Unique molecular identifiers (UMIs) and sample barcodes were introduced during reverse transcription. Next, cDNA of all samples were pooled, unincorporated primers were digested with Exonuclease I and pre-amplified by single-primer PCR (12 cycles). After quality control of amplified cDNA, the sequencing library was constructed from $1 \mathrm{ng}$ full-length cDNA using the Nextera XT Kit (Illumina). To enrich for barcoded 3 ' ends in the Nextera XT library, a custom i5 primer was used. Library pools were sequenced on an Illumina HiSeq1500 on a rapid flow-cell with paired-end layout. The first read contained the sample barcode and the UMI sequences (16 cycles), while the second read contained the cDNA fragment (50 cycles). Note that UMI sequencing is a $3^{\prime}$ method to count the number of unique transcripts. This procedure has the advantage that not the whole gene length has to be covered and a smaller number of reads compared to full-length RNA sequencing methods is sufficient $[60,61]$.

All samples were mapped against concatenated human (hg19) and mouse (mm10) genomes and gene features were quantified using Ensembl gene models (v75). Gene expression of PDX samples (reads mapped to human) and EL08 samples (reads mapped to mouse) was analyzed separately.

The total number of mapped reads and the number of reads per species (human or mouse) were calculated for each sample. In addition, the percentage of reads per species (human or mouse) was calculated. To calculate the number of expressed genes per sample, UMI counts were normalized such that each sample had a total number of 1 million counts. The comparability of UMIs across experiments was checked with a box plot of logtransformed UMI values. The minimum UMI greater than 0 from each experiment was added to each value to avoid $\log (0)$. A gene was defined as expressed if the UMI count/ million was greater or equal than 1. For PDX samples, only reads mapped to human, for EL08 samples, only reads mapped to mouse were considered.

Gene expression analysis and visualization was done with $\mathrm{R}$ version 3.2 .0 on a $\mathrm{x} 86$ 64-pc-linux-gnu (64-bit) platform under Ubuntu 14.04.2 LTS. Differential gene expression analysis of PDX and EL08-1D2 in coculture (DMSO) compared to PDX and EL08-1D2 alone (monoculture controls) was performed using DESeq2 (Supplementary Data). DESeq2 uses library-size-corrected read count data to find differentially expressed genes and is an error model based on the negative binomial distribution for the read counts. For gene expression analysis, the fits of the negative binomial with a generalized linear model were analyzed. Coefficients (interpreted as the $\log 2$ fold changes) were tested using the Wald test. The false 
discovery rate according to Benjamini-Hochberg was used for multiple testing corrections [62]. Each co-culture cohort (AZA, creno, AZA + creno) was then compared to respective DMSO cohorts and a $\log 2$ fold change for each gene and comparison was calculated (Supplementary Data, "Comparison 1"). Further, for each treatment condition (DMSO, AZA, creno, AZA + creno), log2 fold changes were compared to monoculture controls (Supplementary Data, "Comparison 2"). Those hundred genes with the highest average gene expression difference ("top 100 differentially expressed genes") were sorted by $\log 2$ fold change according to the DMSO sample in ascending order as visualized in a heatmap. Finally, enriched gene ontology and KEGG pathways analysis was performed on the "top 100 differentially expressed genes" (Supplementary Data, "top 100 genes").

\section{Statistical analysis}

Statistical analyses were performed by Student's t-test or repeated measures ANOVA using GraphPad Prism software (GraphPad Inc, La Jolla, CA). Linear regression analyses using Greenhouse-Geisser correction was performed in SPSS 24 software (IBM). $P$ values are presented in the figures where a statistically significant difference was found: ${ }^{*}, P<.05 ;{ }^{* *}, P<.01$; ${ }^{* * *}, P<.001$.

\section{Abbreviations}

AML, acute myeloid leukemia; BLI, bioluminescence imaging; BM, bone marrow; $\mathrm{CFC}$, colony-forming cell assay; $\mathrm{CFU}$, colony-forming unit; LIC, leukemia-initiating cell; LTC, long-term culture assay; MNC, mononuclear cells; PDX, patient-derived xenograft; VAF, variant allele frequency.

\section{Authors contributions}

AKG designed and performed experiments, interpreted data and wrote the manuscript. SW, SH, MTW and BV performed experiments. SG and SB performed bioinformatics analyses. MS and $\mathrm{CZ}$ constructed RNA libraries and performed RNAseq. VG, KD, CP and KSG provided patient samples. VG, $\mathrm{SH}, \mathrm{KD}$ and $\mathrm{CT}$ performed cytogenetics and molecular genetics. MR performed immunohistochemistry. RAJO provided EL08-1D2 cells and conceptual advice on experimental design. IJ provided PDX cells and conceptual advice. UK provided NSG mice, analyzed results and wrote the manuscript. KSG conceived the research, designed experiments, analyzed results and wrote the manuscript. All authors discussed the results and reviewed the final manuscript.

\section{ACKNOWLEDGMENTS}

We thank members of the animal research unit at the TUM for their assistance with NSG experiments.
We thank the German AMLSG study group for access to AML samples, Torsten Haferlach (MLL, Munich) for providing additional TET2-mutated samples and mutational information on selected patients, Florian Heidel (University of Jena) for the kind gift of Ba/F3_FLT3WT and Ba/F3 FLT3-ITD cells, Dieter Saur (TUMM) for expert assistance with BLI imaging and Dirk Metzler for advice on RNAseq analysis. We are grateful to Alexander Hapfelmeier (Institute for Medical Statistics, TUM) for expert advice on linear regression analyses.

\section{CONFLICTS OF INTEREST}

KSG received honoraria from Celgene. All other authors declare no potential conflicts of interest.

\section{FUNDING}

This work was supported by grants from the José Carreras Leukemia Foundation (DJCLS R 14/16 to KSG), the German Research Foundation (FOR2033 B3 and SFB 1243 A9 to KSG and RAJO) and the German Cancer Aid (\#111305 to UK). AKG and SH were supported by grants from the German Cancer Consortium (DKTK).

\section{REFERENCES}

1. Knapper S, Burnett AK, Littlewood T, Kell WJ, Agrawal S, Chopra R, Clark R, Levis MJ, Small D. A phase 2 trial of the FLT3 inhibitor lestaurtinib (CEP701) as firstline treatment for older patients with acute myeloid leukemia not considered fit for intensive chemotherapy. Blood. 2006; 108: 3262-70. https://doi.org/10.1182/ blood-2006-04-015560.

2. Serve H, Krug U, Wagner R, Sauerland MC, Heinecke A, Brunnberg U, Schaich M, Ottmann O, Duyster J, Wandt H, Fischer T, Giagounidis A, Neubauer A, et al. Sorafenib in Combination With Intensive Chemotherapy in Elderly Patients With Acute Myeloid Leukemia: Results From a Randomized, Placebo-Controlled Trial. J Clin Oncol. 2013; 31: 3110-8. https://doi.org/10.1200/JCO.2012.46.4990.

3. Fiedler W, Kayser S, Kebenko M, Janning M, Krauter J, Schittenhelm M, Götze K, Weber D, Göhring G, Teleanu V, Thol F, Heuser M, Döhner K, et al. A phase I/II study of sunitinib and intensive chemotherapy in patients over 60 years of age with acute myeloid leukaemia and activating FLT3mutations. Br J Haematol. 2015; 169: 694-700. https://doi.org/10.1111/bjh.13353.

4. Cortes JE, Kantarjian H, Foran JM, Ghirdaladze D, Zodelava M, Borthakur G, Gammon G, Trone D, Armstrong RC, James J, Levis M. Phase I study of quizartinib administered daily to patients with relapsed or refractory acute myeloid leukemia irrespective of FMSlike tyrosine kinase 3-internal tandem duplication status. J Clin Oncol. 2013; 31: 3681-7. https://doi.org/10.1200/ JCO.2013.48.8783. 
5. Heidel F, Solem FK, Breitenbuecher F, Lipka DB, Kasper S, Thiede MH, Brandts C, Serve H, Roesel J, Giles F, Feldman E, Ehninger G, Schiller GJ, et al. Clinical resistance to the kinase inhibitor PKC412 in acute myeloid leukemia by mutation of Asn-676 in the FLT3 tyrosine kinase domain. Blood. 2006; 107: 293-300. https://doi.org/10.1182/ blood-2005-06-2469.

6. Smith CC, Lin K, Stecula A, Sali A, Shah NP. FLT3 D835 mutations confer differential resistance to type II FLT3 inhibitors. Leukemia. 2015; 29: 2390-2. https://doi. org/10.1038/leu.2015.165.

7. Kreso A, Dick JE. Evolution of the cancer stem cell model. Cell Stem Cell. 2014; 14: 275-91. https://doi.org/10.1016/j. stem.2014.02.006.

8. Gerber JM, Smith BD, Ngwang B, Zhang H, Vala MS, Morsberger L, Galkin S, Collector MI, Perkins B, Levis MJ, Griffin CA, Sharkis SJ, Borowitz MJ, et al. A clinically relevant population of leukemic CD34(+)CD38(-) cells in acute myeloid leukemia. Blood. 2012; 119: 3571-7. https:// doi.org/10.1182/blood-2011-06-364182.

9. Parmar A, Marz S, Rushton S, Holzwarth C, Lind K, Kayser S, Döhner K, Peschel C, Oostendorp RAJ, Götze KS. Stromal niche cells protect early leukemic FLT3-ITD+ progenitor cells against first-generation FLT3 tyrosine kinase inhibitors. Cancer Research. 2011; 71: 4696-706. https://doi.org/10.1158/0008-5472.CAN-10-4136.

10. Ravandi F, Alattar ML, Grunwald MR, Rudek MA, Rajkhowa T, Richie MA, Pierce S, Daver N, Garcia-Manero G, Faderl S, Nazha A, Konopleva M, Borthakur G, et al. Phase 2 study of azacytidine plus sorafenib in patients with acute myeloid leukemia and FLT-3 internal tandem duplication mutation. Blood. 2013; 121: 4655-62. https:// doi.org/10.1182/blood-2013-01-480228.

11. Chang E, Ganguly S, Rajkhowa T, Gocke CD, Levis $\mathrm{M}$, Konig H. The combination of FLT3 and DNA methyltransferase inhibition is synergistically cytotoxic to FLT3/ITD acute myeloid leukemia cells. Leukemia. 2016; 30: 1025-32. https://doi.org/10.1038/leu.2015.346.

12. Strati P, Kantarjian H, Ravandi F, Nazha A, Borthakur G, Daver N, Kadia T, Estrov Z, Garcia-Manero G, Konopleva M, Rajkhowa T, Durand M, Andreeff M, et al. Phase I/ II trial of the combination of midostaurin (PKC412) and 5-azacytidine for patients with acute myeloid leukemia and myelodysplastic syndrome. Am J Hematol. 2015; 90: 276-81. https://doi.org/10.1002/ajh.23924.

13. Smith CC, Lasater EA, Lin KC, Wang Q, McCreery MQ, Stewart WK, Damon LE, Perl AE, Jeschke GR, Sugita M, Carroll M, Kogan SC, Kuriyan J, et al. Crenolanib is a selective type I pan-FLT3 inhibitor. Proc Natl Acad Sci USA. 2014; 111: 5319-24. https://doi.org/10.1073/ pnas. 1320661111.

14. Galanis A, Ma H, Rajkhowa T, Ramachandran A, Small D, Cortes J, Levis M. Crenolanib is a potent inhibitor of
FLT3 with activity against resistance-conferring point mutants. Blood. 2014; 123: 94-100. https://doi.org/10.1182/ blood-2013-10-529313.

15. Zimmerman EI, Turner DC, Buaboonnam J, Hu S, Orwick S, Roberts MS, Janke LJ, Ramachandran A, Stewart CF, Inaba H, Baker SD. Crenolanib is active against models of drug-resistant FLT3-ITD-positive acute myeloid leukemia. Blood. 2013; 122: 3607-15. https://doi.org/10.1182/ blood-2013-07-513044.

16. Dombret H, Seymour JF, Butrym A, Wierzbowska A, Selleslag D, Jang JH, Kumar R, Cavenagh J, Schuh AC, Candoni A, Recher C, Sandhu I, Bernal del Castillo T, et al. International phase 3 study of azacitidine vs conventional care regimens in older patients with newly diagnosed AML with $>30 \%$ blasts. Blood. 2015; 126: 291-9. https://doi. org/10.1182/blood-2015-01-621664.

17. Muller-Tidow C, Tschanter P, Röllig C, Thiede C, Koschmieder A, Stelljes M, Koschmieder S, Dugas M, Gerss J, Butterfaß-Bahloul T, Wagner R, Eveslage M, Thiem U, et al. Azacitidine in combination with intensive induction chemotherapy in older patients with acute myeloid leukemia: The AML-AZA trial of the Study Alliance Leukemia. Leukemia. 2016; 30: 555-61. https:// doi.org/10.1038/leu.2015.306.

18. Platzbecker U, Wermke M, Radke J, Oelschlaegel U, Seltmann F, Kiani A, Klut IM, Knoth H, llig CRO, Schetelig J, Mohr B, Graehlert X, Ehninger G, et al. Azacitidine for treatment of imminent relapse in MDS or AML patients after allogeneic HSCT: results of the RELAZA trial. Leukemia. 2012; 26: 381-9. https://doi.org/10.1038/ leu.2011.234.

19. Sato T, Yang X, Knapper S, White P, Smith BD, Galkin S, Small D, Burnett A, Levis M. FLT3 ligand impedes the efficacy of FLT3 inhibitors in vitro and in vivo. Blood. 2011; 117: 3286-93. https://doi.org/10.1182/ blood-2010-01-266742.

20. Papaemmanuil E, Gerstung M, Bullinger L, Gaidzik VI, Paschka P, Roberts ND, Potter NE, Heuser M, Thol F, Bolli N, Gundem G, Van Loo P, Martincorena I, et al. Genomic Classification and Prognosis in Acute Myeloid Leukemia. N Engl J Med. 2016; 374: 2209-21. https://doi.org/10.1056/ NEJMoa1516192.

21. Metzeler KH, Herold T, Rothenberg-Thurley M, Amler S, Sauerland MC, Görlich D, Schneider S, Konstandin NP, Dufour A, Bräundl K, Ksienzyk B, Zellmeier E, Hartmann $\mathrm{L}$, et al. Spectrum and prognostic relevance of driver gene mutations in acute myeloid leukemia. Blood. 2016; 128: 686-98. https://doi.org/10.1182/blood-2016-01-693879.

22. Itzykson R, Kosmider O, Cluzeau T, Mansat-De Mas V, Dreyfus F, Beyne-Rauzy O, Quesnel B, Vey N, Gelsi-Boyer V, Raynaud S, Preudhomme C, Adès L, Fenaux P, Fontenay M; Groupe Francophone des Myelodysplasies (GFM) Impact of TET2 mutations on response rate to azacitidine 
in myelodysplastic syndromes and low blast count acute myeloid leukemias. Leukemia. 2011; 25: 1147-52. https:// doi.org/10.1038/leu.2011.71.

23. Bejar R, Lord A, Stevenson K, Bar-Natan M, Pérez-Ladaga A, Zaneveld J, Wang H, Caughey B, Stojanov P, Getz G, Garcia-Manero G, Kantarjian H, Chen R, et al. TET2 mutations predict response to hypomethylating agents in myelodysplastic syndrome patients. Blood. 2014; 124: 2705-12. https://doi.org/10.1182/blood-2014-06-582809.

24. Traina F, Visconte V, Elson P, Tabarroki A, Jankowska AM, Hasrouni E, Sugimoto Y, Szpurka H, Makishima H, O'Keefe CL, Sekeres MA, Advani AS, Kalaycio M, et al. Impact of molecular mutations on treatment response to DNMT inhibitors in myelodysplasia and related neoplasms. Leukemia. 2014; 28: 78-87. https://doi.org/10.1038/ leu.2013.269.

25. Diesch J, Zwick A, Garz AK, Palau A, Buschbeck M, Götze KS. A clinical-molecular update on azanucleosidebased therapy for the treatment of hematologic cancers. Clin Epigenetics. 2016; 8: 202. https://doi.org/10.1186/ s13148-016-0237-y.

26. Tabe Y, Jin L, Tsutsumi-Ishii Y, Xu Y, McQueen T, Priebe W, Mills GB, Ohsaka A, Nagaoka I, Andreeff M, Konopleva M. Activation of integrin-linked kinase is a critical prosurvival pathway induced in leukemic cells by bone marrow-derived stromal cells. Cancer Research. 2007; 67: 684-94. https://doi.org/10.1158/0008-5472.CAN-06-3166.

27. Zhou J, Bi C, Janakakumara JV, Liu SC, Chang WJ, Tay KG, Poon LF, Xie Z, Palaniyandi S, Yu H, Glaser KB, Albert DH, Davidsen SK, et al. Enhanced activation of STAT pathways and overexpression of survivin confer resistance to FLT3 inhibitors and could be therapeutic targets in AML. Blood. 2009; 113: 4052-62. https://doi. org/10.1182/blood-2008-05-156422.

28. Tabe Y, Shi YX, Zeng Z, Jin L, Shikami M, Hatanaka Y, Miida T, Hsu FJ, Andreeff M, Konopleva M. TGF$\beta$-Neutralizing Antibody 1D11 Enhances CytarabineInduced Apoptosis in AML Cells in the Bone Marrow Microenvironment. Rameshwar P, editor. PLoS ONE. 2013; 8: e62785. https://doi.org/10.1371/journal.pone.0062785.

29. Al-Jamal HAN, Mat Jusoh SA, Hassan R, Johan MF. Enhancing SHP-1 expression with 5-azacytidine may inhibit STAT3 activation and confer sensitivity in lestaurtinib (CEP-701)-resistant FLT3-ITD positive acute myeloid leukemia. BMC Cancer. 2015; 15: 869. https://doi. org/10.1186/s12885-015-1695-x.

30. Chan SM, Majeti R. Role of DNMT3A, TET2, and IDH1/2 mutations in pre-leukemic stem cells in acute myeloid leukemia. Int J Hematol. 2013; 98: 648-57. https://doi. org/10.1007/s12185-013-1407-8.

31. Levis M, Murphy KM, Pham R, Kim KT, Stine A, Li L, McNiece I, Smith BD, Small D. Internal tandem duplications of the FLT3 gene are present in leukemia stem cells. Blood. 2005; 106: 673-80. https://doi.org/10.1182/ blood-2004-05-1902.
32. Pollard JA, Alonzo TA, Gerbing RB, Woods WG, Lange BJ, Sweetser DA, Radich JP, Bernstein ID, Meshinchi S. FLT3 internal tandem duplication in CD34+/CD33- precursors predicts poor outcome in acute myeloid leukemia. Blood. 2006; 108: 2764-9. https://doi.org/10.1182/ blood-2006-04-012260.

33. Taussig DC, Pearce DJ, Simpson C, Rohatiner AZ, Lister TA, Kelly G, Luongo JL, Danet-Desnoyers GA, Bonnet D. Hematopoietic stem cells express multiple myeloid markers: implications for the origin and targeted therapy of acute myeloid leukemia. Blood. 2005; 106: 4086-92. https://doi.org/10.1182/blood-2005-03-1072.

34. Goardon N, Marchi E, Atzberger A, Quek L, Schuh A, Soneji S, Woll P, Mead A, Alford KA, Rout R, Chaudhury S, Gilkes A, Knapper S, et al. Coexistence of LMPP-like and GMP-like Leukemia Stem Cells in Acute Myeloid Leukemia. Cancer Cell. 2011; 19: 138-52. https://doi. org/10.1016/j.ccr.2010.12.012.

35. Corces-Zimmerman MR, Hong WJ, Weissman IL, Medeiros BC, Majeti R. Preleukemic mutations in human acute myeloid leukemia affect epigenetic regulators and persist in remission. Proceedings of the National Academy of Sciences. 2014; 111: 2548-53. https://doi.org/10.1073/ pnas. 1324297111 .

36. Shlush LI, Zandi S, Mitchell A, Chen WC, Brandwein JM, Gupta V, Kennedy JA, Schimmer AD, Schuh AC, Yee KW, McLeod JL, Doedens M, Medeiros JJF, et al. Identification of pre-leukaemic haematopoietic stem cells in acute leukaemia. Nature. 2014; 506: 328-33. https://doi. org/10.1038/nature13038.

37. Weisberg E, Wright RD, McMillin DW, Mitsiades C, Ray A, Barrett R, Adamia S, Stone R, Galinsky I, Kung AL, Griffin JD. Stromal-mediated protection of tyrosine kinase inhibitor-treated BCR-ABL-expressing leukemia cells. Mol Cancer Ther. 2008; 7: 1121-9. https://doi.org/10.1158/15357163.MCT-07-2331.

38. Meads MB, Hazlehurst LA, Dalton WS. The bone marrow microenvironment as a tumor sanctuary and contributor to drug resistance. Clinical Cancer Research. 2008; 14: 2519 26. https://doi.org/10.1158/1078-0432.CCR-07-2223.

39. Stresemann C, Lyko F. Modes of action of the DNA methyltransferase inhibitors azacytidine and decitabine. International Journal of Cancer. 2008; 123: 8-13. https:// doi.org/10.1002/ijc.23607.

40. Aimiuwu J, Wang H, Chen P, Xie Z, Wang J, Liu S, Klisovic R, Mims A, Blum W, Marcucci G, Chan KK. RNA-dependent inhibition of ribonucleotide reductase is a major pathway for 5-azacytidine activity in acute myeloid leukemia. Blood. 2012; 119: 5229-38. https://doi. org/10.1182/blood-2011-11-382226.

41. Marcucci G, Silverman L, Eller M, Lintz L, Beach CL. Bioavailability of azacitidine subcutaneous versus intravenous in patients with the myelodysplastic syndromes. J Clin Pharmacol. 2005; 45: 597-602. https://doi. org/10.1177/0091270004271947. 
42. Hollenbach PW, Nguyen AN, Brady H, Williams M, Ning Y, Richard N, Krushel L, Aukerman SL, Heise C, MacBeth KJ. A comparison of azacitidine and decitabine activities in acute myeloid leukemia cell lines. PLoS ONE. 2010; 5: e9001. https://doi.org/10.1371/journal.pone.0009001.

43. The Cancer Genome Atlas Research Network. Genomic and Epigenomic Landscapes of Adult De Novo Acute Myeloid Leukemia. N Engl J Med. 2013; 368: 2059-74. https://doi. org/10.1056/NEJMoa1301689.

44. Thiede C, Steudel C, Mohr B, Schaich M, Schäkel U, Platzbecker U, Wermke M, Bornhäuser M, Ritter M, Neubauer A, Ehninger G, Illmer T. Analysis of FLT3activating mutations in 979 patients with acute myelogenous leukemia: association with FAB subtypes and identification of subgroups with poor prognosis. Blood. 2002; 99: 432635. https://doi.org/10.1182/blood.V99.12.4326.

45. Schlenk RF, Kayser S, Bullinger L, Kobbe G, Casper J, Ringhoffer M, Held G, Brossart P, Lübbert M, Salih HR, Kindler T, Horst HA, Wulf G, et al. Differential impact of allelic ratio and insertion site in FLT3-ITD-positive AML with respect to allogeneic transplantation. Blood. 2014; 124: 3441-9. https://doi.org/10.1182/blood-2014-05-578070.

46. Vick B, Rothenberg M, Sandhöfer N, Carlet M, Finkenzeller C, Krupka C, Grunert M, Trumpp A, Corbacioglu S, Ebinger M, André MC, Hiddemann W, Schneider S, et al. An advanced preclinical mouse model for acute myeloid leukemia using patients' cells of various genetic subgroups and in vivo bioluminescence imaging. Sbarba Dello P, editor. PLoS ONE. 2015; 10: e0120925. https://doi. org/10.1371/journal.pone.0120925.

47. Townsend EC, Murakami MA, Christodoulou A, Christie AL, Köster J, DeSouza TA, Morgan EA, Kallgren SP, Liu H, Wu SC, Plana O, Montero J, Stevenson KE, et al. The Public Repository of Xenografts Enables Discovery and Randomized Phase II-like Trials in Mice. Cancer Cell. 2016; 29: 574-86. https://doi.org/10.1016/j.ccell.2016.03.008.

48. Schlenk RF, Döhner K, Krauter J, Fröhling S, Corbacioglu A, Bullinger L, Habdank M, Späth D, Morgan M, Benner A, Schlegelberger B, Heil G, Ganser A, et al. Mutations and treatment outcome in cytogenetically normal acute myeloid leukemia. N Engl J Med. 2008; 358: 1909-18. https://doi. org/10.1056/NEJMoa074306.

49. Shih AH, Jiang Y, Meydan C, Shank K, Pandey S, Barreyro L, Antony-Debre I, Viale A, Socci N, Sun Y, Robertson A, Cavatore M, de Stanchina E, et al. Mutational cooperativity linked to combinatorial epigenetic gain of function in acute myeloid leukemia. Cancer Cell. 2015; 27: 502-15. https:// doi.org/10.1016/j.ccell.2015.03.009.

50. Yang L, Rodriguez B, Mayle A, Park HJ, Lin X, Luo M, Jeong M, Curry CV, Kim SB, Ruau D, Zhang X, Zhou T, Zhou M, et al. DNMT3A Loss Drives Enhancer Hypomethylation in FLT3-ITD-Associated Leukemias.
Cancer Cell. 2016; 29: 922-34. https://doi.org/10.1016/j. ccell.2016.05.003.

51. Figueroa ME, Abdel-Wahab O, Lu C, Ward PS, Patel J, Shih A, Li Y, Bhagwat N, Vasanthakumar A, Fernandez HF, Tallman MS, Sun Z, Wolniak K, et al. Leukemic IDH1 and IDH2 Mutations Result in a Hypermethylation Phenotype, Disrupt TET2 Function, and Impair Hematopoietic Differentiation. Cancer Cell. 2010; 18: 553-67. https://doi. org/10.1016/j.ccr.2010.11.015.

52. Metzeler KH, Walker A, Geyer S, Garzon R, Klisovic RB, Bloomfield CD, Blum W, Marcucci G. DNMT3A mutations and response to the hypomethylating agent decitabine in acute myeloid leukemia. Leukemia. 2011; 26: 1106-7. https://doi.org/10.1038/leu.2011.342.

53. DiNardo CD, Patel KP, Garcia-Manero G, Luthra R, Pierce S, Borthakur G, Jabbour E, Kadia T, Pemmaraju N, Konopleva M, Faderl S, Cortes J, Kantarjian HM, et al. Lack of association of IDH1, IDH2and DNMT3Amutations with outcome in older patients with acute myeloid leukemia treated with hypomethylating agents. Leuk Lymphoma. 2014; 55: 1925-9. https://doi.org/10.3109/10428194.2013 .855309 .

54. Stresemann C, Lyko F. Modes of action of the DNA methyltransferase inhibitors azacytidine and decitabine. Int J Cancer. 2008; 123: 8-13. https://doi.org/10.1002/ ijc. 23607.

55. Stone RM, Mandrekar SJ, Sanford BL, Laumann K, Geyer S, Bloomfield CD, Thiede C, Prior TW, Döhner K, Marcucci G, Lo-Coco F, Klisovic RB, Wei A, et al. Midostaurin plus Chemotherapy for Acute Myeloid Leukemia with a FLT3 Mutation. N Engl J Med. 2017; 377: 454-64. https://doi. org/10.1056/NEJMoa1614359.

56. Arreba-Tutusaus P, Mack TS, Bullinger L, Schnöder TM, Polanetzki A, Weinert S, Ballaschk A, Wang Z, Deshpande AJ, Armstrong SA, Döhner K, Fischer T, Heidel FH. Impact of FLT3-ITD location on sensitivity to TKI-therapy in vitro and in vivo. Leukemia. 2016; 30: 1227-31. https://doi. org/10.1038/leu.2015.292.

57. Ye K, Schulz MH, Long Q, Apweiler R, Ning Z. Pindel: a pattern growth approach to detect break points of large deletions and medium sized insertions from paired-end short reads. Bioinformatics. 2009; 25: 2865-71. https://doi. org/10.1093/bioinformatics/btp394.

58. Li H, Durbin R. Fast and accurate long-read alignment with Burrows-Wheeler transform. Bioinformatics. 2010; 26: 589-95. https://doi.org/10.1093/bioinformatics/btp698.

59. Seidler B, Schmidt A, Mayr U, Nakhai H, Schmid RM, Schneider G, Saur D. A Cre-loxP-based mouse model for conditional somatic gene expression and knockdown in vivo by using avian retroviral vectors. Proc Natl Acad Sci USA. 2008; 105: 10137-42. https://doi.org/10.1073/ pnas. 0800487105 . 
60. Parekh S, Ziegenhain C, Vieth B, Enard W, Hellmann I. The impact of amplification on differential expression analyses by RNA-seq. Sci Rep. 2016; 6: 1-11. https://doi. org/10.1038/srep25533.

61. Liu Y, Zhou J, White K. RNA-seq differential expression studies: more sequence or more replication? Bioinformatics.
2014; : 1-4. https://doi.org/10.1093/bioinformatics/btt688/-/ DC1.

62. Love MI, Huber W, Anders S. Moderated estimation of fold change and dispersion for RNA-seq data with DESeq2. Genome Biol. 2014; 15: 550. https://doi.org/10.1186/ s13059-014-0550-8. 